\title{
Tectonic Inheritance During Plate Boundary Evolution in Southern California Constrained From Seismic Anisotropy
}

\section{Journal Article}

Author(s):

Schulte-Pelkum, Vera; Becker, Thorsten W.; Behr, Whitney M.; Miller, Meghan S.

Publication date:

2021-11

Permanent link:

https://doi.org/10.3929/ethz-b-000517497

Rights / license:

Creative Commons Attribution 4.0 International

Originally published in:

Geochemistry, Geophysics, Geosystems 22(11), https://doi.org/10.1029/2021gc010099 


\section{Geochemistry, Geophysics, Geosystems}

\author{
RESEARCH ARTICLE \\ 10.1029/2021GC010099 \\ Key Points: \\ - Seismicity, geodesy, and seismic \\ anisotropy provide depth-dependent \\ deformation markers for southern \\ California crust and mantle \\ - Surface velocity gradients, coseismic \\ strain, and SKS splitting are \\ all broadly consistent with N-S \\ compression/E-W extension \\ - Shallow splitting, receiver functions, \\ $P$, and $P_{n}$ suggest fabric inherited \\ from past tectonic episodes \\ dominates in the lithosphere
}

Correspondence to:

V. Schulte-Pelkum,

verasp@colorado.edu

\section{Citation:}

Schulte-Pelkum, V., Becker, T. W., Behr, W. M., \& Miller, M. S. (2021). Tectonic inheritance during plate boundary evolution in southern California constrained from seismic anisotropy. Geochemistry, Geophysics, Geosystems, 22, e2021GC010099. https://doi. org/10.1029/2021GC010099

Received 11 AUG 2021 Accepted 26 OCT 2021

\section{Tectonic Inheritance During Plate Boundary Evolution in Southern California Constrained From Seismic Anisotropy}

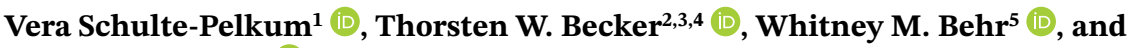 \\ Meghan S. Miller ${ }^{6}$ (D)
}

${ }^{1}$ Cooperative Institute for Research in Environmental Sciences and Department of Geological Sciences, University of Colorado Boulder, Boulder, CO, USA, ${ }^{2}$ Jackson School of Geosciences, Institute for Geophysics, University of Texas at Austin, Austin, TX, USA, ${ }^{3}$ Department of Geological Sciences, Jackson School of Geosciences, University of Texas at Austin, Austin, TX, USA, ${ }^{4}$ Oden Institute for Computational Engineering and Sciences, University of Texas at Austin, Austin, TX, USA, ${ }^{5}$ Geological Institute, Eidgenössische Technische Hochschule Zürich, Zürich, Switzerland, ${ }^{6}$ Research School of Earth Sciences, Australian National University, Canberra, ACT, Australia
(C) 2021. The Authors.

This is an open access article under the terms of the Creative Commons Attribution License, which permits use, distribution and reproduction in any medium, provided the original work is properly cited.

\begin{abstract}
The style of convective force transmission to plates and strain-localization within and underneath plate boundaries remain debated. To address some of the related issues, we analyze a range of deformation indicators in southern California from the surface to the asthenosphere. Present-day surface strain rates can be inferred from geodesy. At seismogenic crustal depths, stress can be inferred from focal mechanisms and splitting of shear waves from local earthquakes via crack-dependent seismic velocities. At greater depths, constraints on rock fabrics are obtained from receiver function anisotropy, $P_{n}$ and $P$ tomography, surface wave tomography, and splitting of $S K S$ and other teleseismic core phases. We construct a synthesis of deformation-related observations focusing on quantitative comparisons of deformation style. We find consistency with roughly N-S compression and E-W extension near the surface and in the asthenospheric mantle. However, all lithospheric anisotropy indicators show deviations from this pattern. $P_{n}$ fast axes and dipping foliations from receiver functions are fault-parallel with no localization to fault traces and match post-Farallon block rotations in the Western Transverse Ranges. Local shear wave splitting orientations deviate from the stress orientations inferred from focal mechanisms in significant portions of the area. We interpret these observations as an indication that lithospheric fabric, developed during Farallon subduction and subsequent extension, has not been completely reset by present-day transform motion and may influence the current deformation behavior. This provides a new perspective on the timescales of deformation memory and lithosphere-asthenosphere interactions.
\end{abstract}

Plain Language Summary While structural geologists can interpret orientations of rock fabric in exposures at the surface to make inferences on how the rock deformed in the past, geophysical measurements usually only offer snapshots of present-day conditions below the surface. An exception is offered by several geophysical methods that allow measurements of rock fabric below the surface. Such measurements are sensitive to different depths in the Earth's crust and mantle. We combine existing measurements from southern California to test how deep rock fabric compares to what we can measure in terms of present-day surface deformation. While the region is currently under strike-slip deformation, with the Pacific plate sliding horizontally northwestward relative to the North American plate along the San Andreas Fault, markers of deformation at depth do not consistently line up with the present day motion. We infer that deep rock fabric has an imprinted memory from past deformation episodes when the region underwent compression in a subduction zone and extension in subsequent episodes. This deep rock memory persists to this date and may influence how the region deforms currently.

\section{Introduction}

Southern California hosts one of the world's best-instrumented and most thoroughly studied transform plate boundaries, yet questions as to how surface deformation transitions to convective flow and deformation at depth remain. Present-day transform motion is accommodated on the San Andreas Fault (SAF) (Figure 1) 


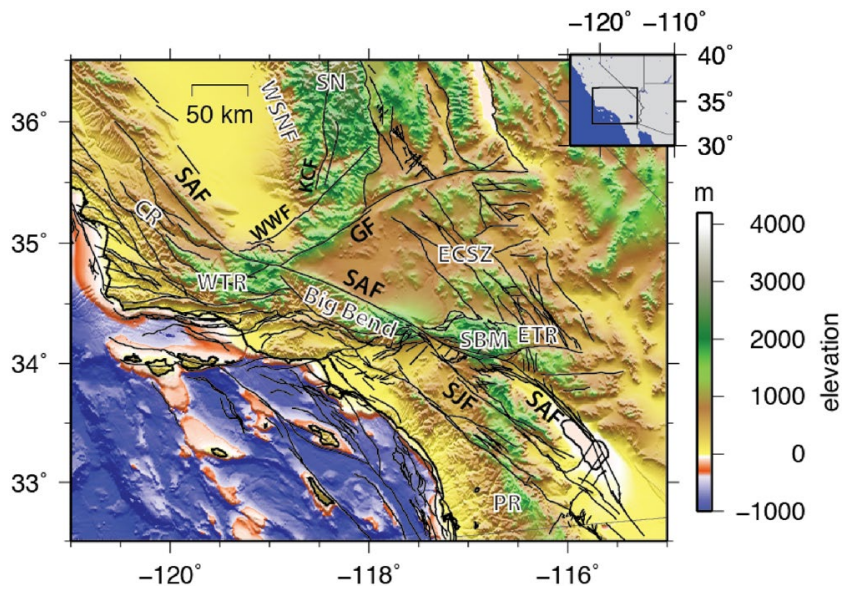

Figure 1. Map of the study area with shaded topography and elements referred to in text (larger context shown in inset with main map area outline drawn). Black lines are faults from the SCEC Community Fault Model (CFM) version 5.3 (Plesch et al., 2007). SN, Sierra Nevada; WSNF, western Sierra Nevada foothills; SAF, San Andreas Fault; KCF, Kern Canyon Fault; WWF, White Wolf Fault; CR, Coast Ranges; WTR, Western Transverse Ranges; GF, Garlock Fault; ECSZ, Eastern California shear zone; SBM, San Bernardino Mountains, which form part of the ETR, Eastern Transverse Ranges; SJF, San Jacinto Fault; PR, Peninsular Ranges. and the major fault strands to the west, such as the San Jacinto Fault and offshore faults of the Continental Borderland; as well as to the east within the Eastern California shear zone (Figure 1) (e.g., Becker et al., 2005; Bennett et al., 1996; Bourne et al., 1998; Chuang \& Johnson, 2011; E. H. Hearn, 2019; Meade \& Hager, 2005; Y. Zeng \& Shen, 2016, 2017). The SAF itself forms a large-scale restraining bend in southern California such that many active faults are range-bounding thrusts and/or obliqueslip faults with potentially complex geometries and intersections at depth (e.g., Matti et al., 1993, 1992; Yule \& Sieh, 2003). The tectonic history of the region encompasses long-lived Mesozoic subduction, followed by extensional and transform regimes (Atwater, 1970). Subduction was accompanied by vigorous arc magmatism and emplacement of batholiths that now compose the Sierra Nevada and Peninsular Ranges (Figure 1). These appear to behave as rigid blocks within the present-day kinematic reference frame, but nonetheless preserve Mesozoic magmatic fabrics and fossil ductile shear zones that may influence interpretations of geophysical images. Some subregions underwent significant rotation in addition to translation following the Mesozoic, notably an up to $110^{\circ}$ rotation of the Western Transverse Ranges block (Atwater \& Stock, 1998; McQuarrie \& Wernicke, 2005; Nicholson et al., 1994).

Given the complex tectonic history of the region, it remains a challenge to link different types of geophysical datasets and images to aspects of the present-day and/or long-term deformation regimes. In particular, there are several open questions, including: (a) Do crustal and lithospheric mantle fabric reflect the present-day stress state? What is the timescale for resetting lithospheric rock fabric? (b) Is strain localized on currently active faults and shear zones, and if so, to what distance and depth? Does strain localization cross the brittle-plastic transition? Is lithospheric fabric reset below this transition? Do faults communicate laterally below the brittle-plastic transition? (c) How do asthenospheric processes relate to surface stress? If deep processes drive near-surface stress state, is lithospheric fabric reset to match both in response?

Here we attempt to address some of these questions through synthesizing a wide range of geophysical datasets that provide information about fabric and stress state in southern California, from the surface through the asthenosphere. There have been a number of studies comparing some of the relevant data sets to address these issues with each other already, in particular $S K S$ splitting and focal mechanisms to GNSS velocities to infer shallow stress (Chamberlain et al., 2014; Polet \& Kanamori, 2002; Yang \& Hauksson, 2013) as well as surface wave results (Kosarian et al., 2011), but a comprehensive analysis across all accessible depth ranges as presented here seems to be missing. In particular, we seek to gain resolution in the lithosphere via inclusion of additional data from receiver functions and $P$ and $P_{n}$ tomography. We begin by providing an overview of the geophysical data sets that can be used as stress and strain markers at different crust and mantle depths (Figure 2) and previous results from the literature. We then describe our methods and discuss the results of cross-comparisons in light of the tectonic questions listed above.

\section{Overview of Geophysical Datasets That Can be Used as Stress and Strain Markers in Southern California}

\subsection{Geodetic Constraints}

Present-day surface deformation on decadal scales can be characterized by geodetic constraints (e.g., Flesch et al., 2000; Haines \& Holt, 1993; 
Kreemer et al., 2000; Wei et al., 2010), and gradients of GNSS velocities, for example, yield estimates of the horizontal strain rate tensor at the surface. Such inferences often differ greatly in amplitude, in large part due to choices of interpolation and if and how fault localization is included (e.g., Haines et al., 2015; Sandwell \& Wessel, 2016). Strain rates are also affected by co- and postseismic effects, leading to possible regional temporal bias (e.g., Chuang \& Johnson, 2011; Hearn et al., 2013; Hetland \& Hager, 2006). Despite the uncertainties, however, the broad, $\sim 50 \mathrm{~km}$ length scale patterns of geodetically inferred surface strain rates for our study region are fairly consistent among models (e.g., Kreemer et al., 2014; Sandwell et al., 2009) and we use the SCEC Community Geodetic Model V1 for geodetic strain-rates (Sandwell et al., 2016) in the following. This model consists of an average of a range of GPS-based estimates, but preserves spatial variations on scales similar to those imaged from seismicity, discussed next.

To avoid regions which are poorly constrained in terms of major extensional axes orientations, we only use the signal if the shear strain-rates are $>1.5 \times 10^{-15} \mathrm{~s}^{-1}$, and limit the influence of the sampled datapoints on any interpolated geodetic strain-rates to a circle of $20 \mathrm{~km}$. Similar choices are made for all point-wise datasets based on inferred resolution and sensitivity. These interpolation parameters affect local patterns of comparison maps and numeric values such as average misfits slightly, but overall conclusions are independent of these details.

\subsection{Focal Mechanisms or Moment Tensors}

At seismogenic depths, recent and ongoing deformation can be inferred from focal mechanisms or moment tensors. These provide direct constraints on co-seismic strain only, and compressional stress orientations can in theory lie anywhere within the compressional quadrant of a single mechanism (McKenzie, 1969). There are a range of approaches to convert a set of mechanisms to a deformation tensor; for example relatively straightforward Kostrov (1974) summation for strain(-rates), or normalized stress-tensor inversions that often assume the direction of slip on the rupture plane is parallel to the orientation of the maximum shear stress (e.g., Michael, 1984). We know that stress inversions are affected by structural heterogeneity (e.g., Gephart \& Forsyth, 1984; Hardebeck \& Michael, 2004; Pollard et al., 1993; Townend \& Zoback, 2004) and different approaches yield different estimates on length scales $\lesssim 10 \mathrm{~km}$ (e.g., Abolfathian et al., 2020). However, Kostrov summed estimates of strain broadly agree with smoothed stress inversions on longer wavelengths (Becker et al., 2005; Hardebeck \& Michael, 2006). We therefore use the stress inversion of Yang and Hauksson (2013), which is of the smoothed Hardebeck and Michael (2006) type and has been adopted as a working model for crustal stress by SCEC. In the comprehensive comparison, we also use our own Kostrov summation of focal mechanisms (Yang et al., 2012), as used by Yang and Hauksson (2013) with a temporally more limited catalog, and simple binning with $0.25^{\circ}$ boxes. Given the comparison with seismic anisotropy below, we here focus on the horizontal, orientational quantities that can be derived from strain (rate) or stress tensors, that is the major compressional or extensional axes of the principal component system, and assume temporal stationarity.

\subsection{Local Event Shear-Wave Splitting}

A more indirect measure of the shallow crustal stress is given by splitting of shear waves from local earthquakes, arriving on steep paths to stations above. The shear wave component polarized parallel to cracks will propagate faster than its orthogonal counterpart; since stress will control crack closure and formation, this leads one to expect fast polarization orientations that match the compressive stress orientation (e.g., Crampin \& Chastin, 2003). The most recent complete analysis of local splitting in the study region is by $\mathrm{Z}$. Li and Peng (2017) who note that this expected relationship breaks down over significant portions of the region, including in the vicinity of major strike-slip faults. Comparison of local shear wave splitting with stress inferences from boreholes indicates that complexities are expected, for example because of shallow fabric rather than crack-stress control (Boness \& Zoback, 2006). There are other, more direct indicators of crustal stress from boreholes, but those are not available widely enough, nor are they sampling on the appropriate scales for our study (Luttrell \& Hardebeck, 2021; Persaud et al., 2020). 


\subsection{Receiver Functions}

Receiver function arrivals show strong variations in arrival amplitude and polarity with backazimuth in our study region, and arrivals with a $360^{\circ}$ dependence with backazimuth (first azimuthal harmonic) can be interpreted as conversions from contrasts in crustal seismic anisotropy with a plunging symmetry axis, such as dipping foliation (Brownlee et al., 2017; Porter et al., 2011; Schulte-Pelkum, Ross, et al., 2020). Unlike splitting methods such as local event shear wave, $S K S$, or receiver function Moho $P$-to- $S$ conversion (PS) splitting analyses, this method is not a cumulative measurement of shear wave anisotropy and instead is sensitive to changes in $P$ anisotropy (Bianchi et al., 2010; Levin \& Park, 1998; Park \& Levin, 2016). It therefore allows resolving the depth of anisotropic contrasts and is sensitive to shear zones with thicknesses ¿2 km (Liu \& Park, 2017; Schulte-Pelkum \& Mahan, 2014a, 2014b). Azimuthally varying receiver function conversions have higher amplitudes and therefore better sensitivity for plunging axis symmetry, for example dipping foliation, compared to horizontal symmetry axes or purely azimuthal anisotropy (Brownlee et al., 2017; Park \& Levin, 2016; Schulte-Pelkum \& Mahan, 2014b). Studies modeling observed receiver function arrivals in the southern and central California region find plunging symmetry axes in the crust, including at middle and lower crustal depths, with foliations paralleling major faults (Audet, 2015) or perpendicular to Farallon convergence (Porter et al., 2011). A simpler method that determines foliation strike without waveform modeling (Schulte-Pelkum \& Mahan, 2014a, 2014b) shows surface fault-parallel strikes with a pervasive lithospheric fabric that was interpreted as tectonic inheritance from previous compressional and extensional episodes (Schulte-Pelkum, Ross, et al., 2020).

\subsection{Regional Phase $P_{n}$ and Teleseismic $P$ Wave Tomography}

The regional seismic phase $P_{n}$ propagates horizontally as a headwave in the uppermost mantle immediately beneath the Moho. Azimuthal variations in its propagation speed are used to measure horizontal axis seismic anisotropy (Buehler \& Shearer, 2010, 2012, 2014, 2017; T. M. Hearn, 1996; G. P. Smith \& Ekström, 1999), reflecting lithospheric mantle fabric. Studies either solve for isotropic and anisotropic structure using tomography (Buehler \& Shearer, 2010, 2014, 2017; T. M. Hearn, 1996) or analyze localized azimuthal variations using station subsets (Buehler \& Shearer, 2012; G. P. Smith \& Ekström, 1999). The regional fast axes are broadly subparallel to the strike of the SAF, albeit with geographic variations. Joint tomography of local and teleseismic $P$ arrival times can also be used to infer seismic anisotropy (e.g., Bokelmann, 2002), though it is subject to trade-offs between isotropic and anisotropic structure. Consistent with the $P_{n}$ results, a recent, regional anisotropic $P$ wave tomography model shows broadly SAF-parallel fast orientations at lithospheric depths (Yu \& Zhao, 2018).

\subsection{Surface Wave Tomography}

Surface wave tomographic studies in the region resolve isotropic heterogeneity as well as radial anisotropy, with anomalous regions of negative radial anisotropy bordered by the SAF (K. Wang et al., 2020). Continent-wide azimuthal anisotropy studies using surface waves show fast orientations somewhat similar to SKS in the upper mantle and variable anisotropy in the crust (Lin et al., 2011). Regional-scale studies find evidence of azimuthal anisotropy in phase velocities in the area (Qiu et al., 2019), though not in some more localized studies such as for the Parkfield area (X. Zeng \& Thurber, 2019). A surface wave inversion for 3-D azimuthal anisotropy at regional resolution is not available to date.

\subsection{SKS Splitting}

In addition to local event shear wave splitting, there are a multitude of studies that target splitting of much lower-frequency teleseismic core phases such as SKS (Savage \& Silver, 1993). Similar to the case of local event splitting, the teleseismic splitting time delay and fast axis orientation are integrated nonlinearly (Kaviani et al., 2011; Silver \& Long, 2011; Silver \& Savage, 1994a) over the entire raypath, in this case from the core-mantle boundary to the station. The signal is typically interpreted as being dominated by the asthenospheric mantle, with some contribution from the lithosphere and SAF shear (e.g., Savage et al., 2004) and small to negligible influence of the crust (Silver, 1996). While the stress field has nevertheless been invoked to explain SKS splitting in our study region (Polet \& Kanamori, 2002), a more common explanation 
a)

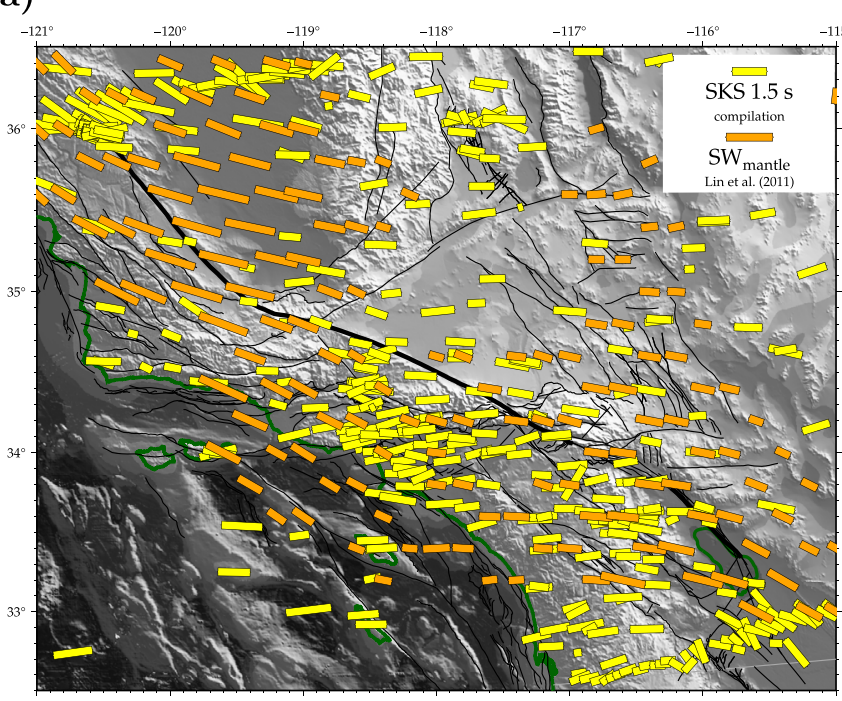

b)

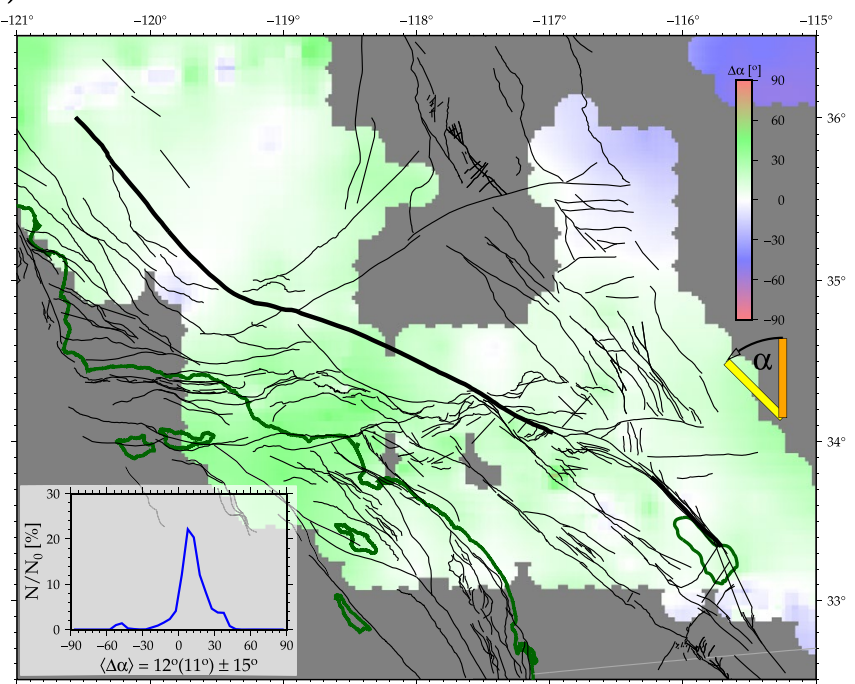

Figure 3. (a) Fast axis orientation and delay time of $S K S$ splits (compilation of Becker et al., 2012, updated as of 2020) and Rayleigh wave upper mantle fast axis and percent anisotropy (orange bars; Lin et al., 2011). Elevation shading and faults are shown for orientation, with fault traces from the SCEC CFM5.3; heavy line for San Andreas Fault, coastlines in green. (b) Signed angular difference comparison between the two orientation sets (color coding of bars in angle sign definition as in (a); amplitude information is not used in this case). Inset shows histogram of the angular differences, with mean(median) and standard deviation indicated; $N$ is number of measurements pairs per bin, $N_{0}$ total number of pairs.

is large-scale mantle flow and asthenospheric convection leading to lattice preferred orientation olivine fabrics (e.g., Becker, Schulte-Pelkum, et al., 2006; Bonnin et al., 2010; Savage \& Sheehan, 2000; Silver \& Holt, 2002; Ramsay et al., 2016; Zhou et al., 2018). Alignment with shear as expected from absolute plate motions does not match the observed orientations well (Bonnin et al., 2010; Silver \& Holt, 2002), but modeling of plate motion and density-driven mantle flow, without any deep shear localization at the plate boundary, captures SKS patterns on scales of $\gtrsim 200 \mathrm{~km}$ (Becker, Schulte-Pelkum, et al., 2006). Nonetheless, small-scale variations in teleseismic splitting across the SAF are observed (Jiang et al., 2018; Özalaybey \& Savage, 1995; Savage et al., 2004), and the role of the SAF in affecting SKS splitting remains debated (e.g., Bonnin et al., 2010; Savage et al., 2004). Depth-dependent splitting studies show SAF-parallel fast orientations in the lithosphere on the northern part of the study area (north of the Garlock fault; Figure 1), although solutions may be ambiguous (Hartog \& Schwartz, 2001; Monteiller \& Chevrot, 2011).

In the following, we synthesize these geodetic, geological, and seismological deformation and stress and strain markers by quantitative comparisons of their orientations across the region.

\section{Methods}

We select published oriented data sets and compilations. Pairs of data sets are compared as shown in Figure 3 as an example. Orientations of collocated pairs of data with amplitude and strike information are plotted against each other in map view as in Figure 3a. A second view for each comparison pair shows the angular deviation on a local footprint as background color (Figure 3b) to highlight geographical variations in angular agreement or disagreement. Statistics of the angle difference over the entire area in which data from both methods are available are calculated and plotted in an inset (example Figure 3b). For this study, we assume all data with azimuthal information to be orientational, or axial, rather than vectorial (e.g., N-S, rather than $\mathrm{N}$ or S). Most data used in this study are indeed axial (fast polarization or propagation orientations, stress and strain axes, shortening or extensional axes). Fault orientations are reduced to unsigned strike, ignoring dip direction. Azimuthal receiver function arrival strikes are signed and offer dip direction information if additional assumptions on the layers bounding a contrast are made, such as sign of a velocity contrast, whether anisotropy is stronger above or below an interface, or whether anisotropy has a fast or slow symmetry axis (Schulte-Pelkum, Ross, et al., 2020). In this study, we use unsigned strikes for receiver functions to compare to other axial quantities, but display the signed orientation in Figure 6c; the short 
arrows point towards downdip if the signal is from the top of an anisotropic layer with slow axis symmetry (such as schists); (Brownlee et al., 2017) or from a slow-over-fast dipping interface between isotropic layers.

Maps such as Figure 3a display amplitude information. The methods under comparison here have different lateral and depth resolutions as well as differences in available lateral data coverage. Some of these variations are reflected in our choice of footprints for orientation comparisons in Figure $3 \mathrm{~b}$ and similar, but for quantitative tests of the lateral and vertical sensitivity for each method, we refer the reader to the original publications. Moreover, each method has different intrinsic sensitivities, for example to anisotropy amplitude. Some methods are cumulative over the volume sampled (shear wave splitting and tomographic methods), while others are sensitive to the strength of contrasts (receiver function azimuthal conversions). A quantitative amplitude comparison would require forward modeling of specific anisotropic models, since the amplitude response depends on details of not only anisotropy strength, but also geometry and orientation, symmetry type, and layering (e.g., Becker, Schulte-Pelkum, et al., 2006; Brownlee et al., 2017; Levin \& Park, 1998; Schulte-Pelkum, Ross, et al., 2020; Silver \& Savage, 1994b; Xie et al., 2017, 2015). Another difficulty in linking deformation to anisotropic strength lies in the fact that there is no simple scaling of strain to anisotropy. For example, the formation of olivine crystallographic preferred orientation (CPO) anisotropy is expected to reach saturation at strains of $\sim 5 . . .10$ (e.g., Bystricky et al., 2000; Skemer \& Hansen, 2016), corresponding to typical asthenospheric advection times of 10s of Myr (e.g., Becker, Chevrot, et al., 2006). When seen as azimuthal anisotropy, for example, significant strength variations then arise due to reorientation and reworking of CPOs (e.g., Castelnau et al., 2009; Hansen et al., 2014). While we display amplitudes (see a complete set of plots in Schulte-Pelkum et al., 2021), we therefore here limit the quantitative comparison between different datasets to orientations and leave the more complex amplitudes for later analysis.

To test whether specific datasets are consistent with the kinematic regime of San Andreas transform right-lateral shear, we plot them relative to each other as well as relative to two possible reference orientations coinciding with the instantaneous and finite strain ellipses, assuming simple shear strain geometry. The right-lateral motion along the Pacific-North America plate boundary is oriented NW-SE, with the Pacific plate moving NW relative to North America. Instantaneous shear strain in a medium deforming under distributed viscous simple shear deformation is expected to show compression and extension at $45^{\circ}$ to the shear plane, in this case, N-S compression and E-W extension. During progressive simple shear, however, the lengthening orientation rotates into the plane of shear (e.g., McKenzie \& Jackson, 1983), so datasets that potentially track high strain fabrics such as ductile foliations or gouge fabrics along faults may show alignment with the finite strain ellipse (SAF-parallel, NW-SE).

We also compare some datasets to the inferred orientation of Farallon paleofoliations. Farallon convergence was oriented NE relative to the North American margin, and we assume paleofoliations formed perpendicular to Farallon convergence orientations, consistent with the general orientation of major Mesozoic-to-early-Tertiary terrane boundaries, faults, and ductile foliations exposed at the surface presently (Dickinson, 1970; Ernst, 1970; Hamilton, 1969; Jacobson et al., 1996). In most of the study area, these paleo-orientations have a similar strike to that of the SAF system. Exceptions are blocks that underwent post-Farallon rotations such as the Western Transverse Ranges (e.g., McQuarrie \& Wernicke, 2005). One may expect deep-seated Farallon-convergence-related paleofoliations to have a shallower dip than transform shear fabric. However, Porter et al. (2011) inferred lower crustal foliation dips with a broad range of dip angles and a mean dip of $55^{\circ}$ from receiver function modeling. Intrusive fabrics may also show steeply dipping foliations.

\section{Results}

\subsection{Mantle/Asthenospheric Depths}

In Figure 3, we compare fast axis orientations from SKS splitting (i.e., inferred orientation of the polarization plane of the fast propagating pulse) from a compilation (update of Becker et al., 2012) to the uppermost mantle layer solution of an isotropic and anisotropic Rayleigh wave inversion using ambient noise as well as earthquake phase dispersion (Lin et al., 2011). Sensitivity of SKS extends from the core-mantle boundary to the surface but is assumed to be dominated by the asthenospheric mantle. The surface wave inversion has depth constraints down to $\sim 100 \mathrm{~km}$ (Lin et al., 2011). This can be compared to an estimated LAB depth 

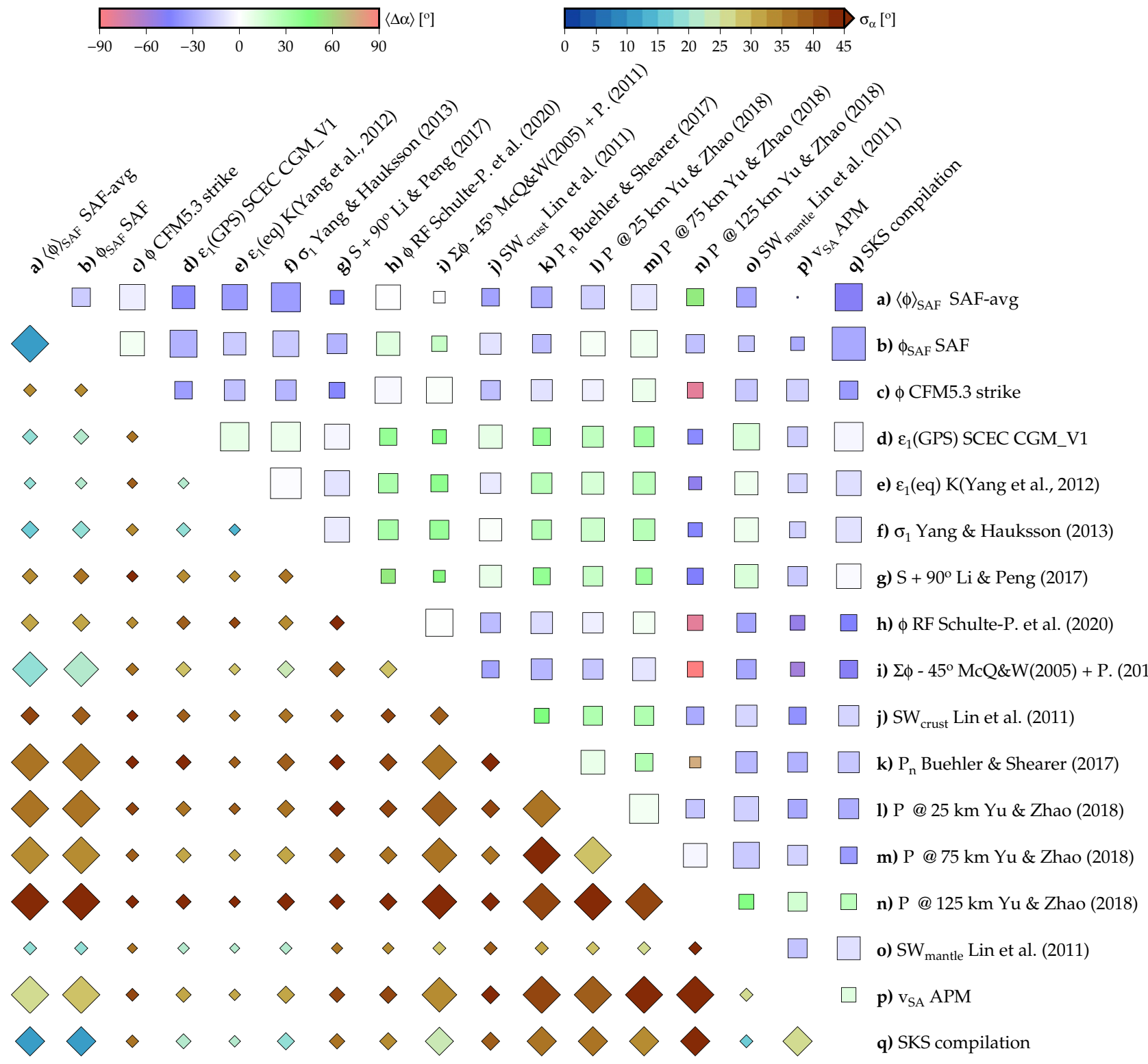

Figure 4. Mean angular difference (squares, scaled by "unimodality," that is unity minus Sarle's bimodality coefficient, $1-\frac{\gamma^{2}+1}{\kappa}$ where $\gamma$ and $\kappa$ are the skewness and kurtosis, respectively) and standard deviation of the distribution (diamonds, scaled by the coverage area, cf. Figure 9 ) for an extended selection of data sets. (a) Mean San Andreas Fault (SAF) strike (single value); (b) SAF fault strike perpendicularly extended from the main fault (both from the PacificNorth America plate boundary from Bird, 2003); (c) local fault strike from SCEC CFM 5.3 (Plesch et al., 2007) (cf. Figure 6); (d) extensional axes from SCEC CGM_V1 (Sandwell et al., 2016) geodetic strain rates (cf. Figure 7); (e) extensional axes of a Kostrov summation of an update of the Yang et al. (2012) focal mechanisms; (f) extensional stress from Yang et al. (2012) based stress inversion (Yang \& Hauksson, 2013) (cf. Figure 7); (g) fast axes from local $S$ splits (Z. Li $\&$ Peng, 2017) plus $90^{\circ}$; (h) fast axes from receiver functions (Schulte-Pelkum, Ross, et al., 2020) (cf. Figure 6); (i) cumulative block rotations from McQuarrie and Wernicke (2005) and Porter et al. (2011) minus 45 (cf. Figure 5); (j) crustal-depth surface wave anisotropy (Lin et al., 2011); (k) $P_{n}$ anisotropy (Buehler $\&$ Shearer, 2017) (cf. Figure 5); (1-n) $P$ tomography fast axes (Yu \& Zhao, 2018) at depths of 25, 75, and $125 \mathrm{~km}$, respectively; (o) mantle depth surface wave anisotropy (Lin et al., 2011) (cf. Figure 3); (p) absolute plate motion (APM) orientations in the spreading-aligned reference frame (Becker et al., 2015); and (q) SKS splitting compilation fast axes (update of Becker et al., 2012) (cf. Figure 3). A PDF provided in Schulte-Pelkum et al. (2021) contains all individual plots and cross-comparisons as well as an equivalent matrix with linked figures.

ranging mostly from 60 to $80 \mathrm{~km}$ (half-width of distribution) in the area inferred from $S p$ receiver functions (Lekic et al., 2011; Levander \& Miller, 2012).

Both sets of observed fast axes are rotated counterclockwise from the SAF (Figure 4 and additional figures in Schulte-Pelkum et al., 2021). The misorientation of SKS relative to the average SAF strike outside of the 
Big Bend is $-52^{\circ}$ (SAF is NW-SE, SKS WSW-ENE), with a standard deviation of $\pm 12^{\circ}$ and a strong unimodal peak of $24 \%$ amplitude (percentage of measurement pairs in the peak bin). The mean and standard deviation are computed accounting for orientational angular misfit $\Delta \alpha \in$ [-90; 90], allowing for a distinction between clockwise and counterclockwise deviation, and based on even area sampling of the region where both data sets provide constraints. The "area of influence" of each data set is seen in the circular regions of Figure $3 \mathrm{~b}$ and chosen based on a rough estimate of averaging width, for example Fresnel zone of SKS.

Mantle depth, surface-wave derived fast axes are slightly less rotated relative to the average strike of the SAF $\left(-36^{\circ} \pm 18^{\circ}\right.$, peak $\left.23 \%\right)$. The average angle difference between $S K S$-fast and mantle surface wave-fast axes is $12^{\circ} \pm 15^{\circ}$ at a strong (23\%) unimodal peak. The largest misalignment is in the Western Transverse Ranges and exceeds $30^{\circ}$ (Figure $3 \mathrm{~b}$ ). The $P$ tomography study by Yu and Zhao 2018) shows only low-amplitude azimuthal anisotropy at depth nodes of 125 and $200 \mathrm{~km}$. Cross-comparisons plots for all datasets and models can be accessed through a linked table in Schulte-Pelkum et al., 2021 with the same quantities shown in Figure 4. Figure 4 also summarizes the median, standard deviation, as well as the degree of unimodality of the angular misfit distributions.

\subsection{Lithospheric Mantle}

Depth-specific constraints for the lithospheric mantle are extracted from $P_{n}$ tomography, localized $P_{n}$ azimuthal velocity variations, and $P$ tomography. While some anisotropic receiver function signals are from structures below the Moho, most are from crustal depths, and receiver function inferred strikes will be discussed in the next section.

Figure 5 shows the angular alignment between $P_{n}$ fast orientations from Buehler and Shearer (2017) and SAF-strike-averaged orientations outside of the Big Bend region applied to the entire study area. Agreement is close in a broad corridor (order $100-200 \mathrm{~km}$ width) around the SAF, with no localization close to the SAF. Notably, the $P_{n}$ fast axes do not change strike along with the SAF in the Big Bend area, and there is no indication of constrictional E-W strikes due to the restraining bend as proposed by Monteiller and Chevrot (2011). The area closest to the SAF trace that shows significant misalignment with average SAF strike is in the Western Transverse Ranges.

To test the possibility that lithospheric mantle fabric is not controlled by present-day shear associated with the SAF system and instead persists from previous tectonic episodes, we compare $P_{n}$ fast axes to Farallon convergence-perpendicular strikes including block rotations since 36 Ma from McQuarrie and Wernicke (2005) with interpolations by Porter et al. (2011). These orientations are a proxy for lithospheric fabric strikes that developed under compression, accretion, and pluton emplacement during long-lived subduction and were subsequently rotated along with the surface of the respective blocks as proposed by for example Atwater and Stock (1998). Agreement is improved in the western part of the Western Transverse Ranges and similar to the SAF comparison case elsewhere.

$P$ anisotropy (Yu \& Zhao, 2018) shows the highest degree of seismic anisotropy in the lithospheric mantle layer (75 km depth grid nodes; compare 60-80 km LAB depths from Lekic et al. (2011)), with fast azimuths fairly well aligned with SAF strike or Farallon paleofabric in the SAF corridor (Figure 4). $P$ anisotropy at $75 \mathrm{~km}$ depth also shows a strong falloff of amplitudes in the Western Transverse Ranges.

\subsection{Crust}

Receiver functions show conversions with $360^{\circ}$ azimuthal periodicity in amplitude (two polarity flips over entire backazimuth range; here called $A_{1}$ ) that originate from contrasts in plunging axis anisotropy, such as dipping foliation, as well as dipping interfaces between isotropic layers (Schulte-Pelkum \& Mahan, 2014b). We interpret both as indicators of tectonic grain (Schulte-Pelkum, Caine, et al., 2020) rather than attempting a distinction by testing for the bent direct $P$ wave present only in the isotropic dipping case (Schulte-Pelkum \& Mahan, 2014b). We use published strikes of such contrasts in our study area from Schulte-Pelkum, Ross, et al. (2020), showing the largest $A_{1}$ amplitude arrival at each station. Depths of these contrasts are concentrated in the crust (Figure 6a, inset and strike bar fill color in Figure 6c). The sign of the azimuthal polarity flips contains information about foliation dip at a contrast or interface dip, but the dip sense is 
a)

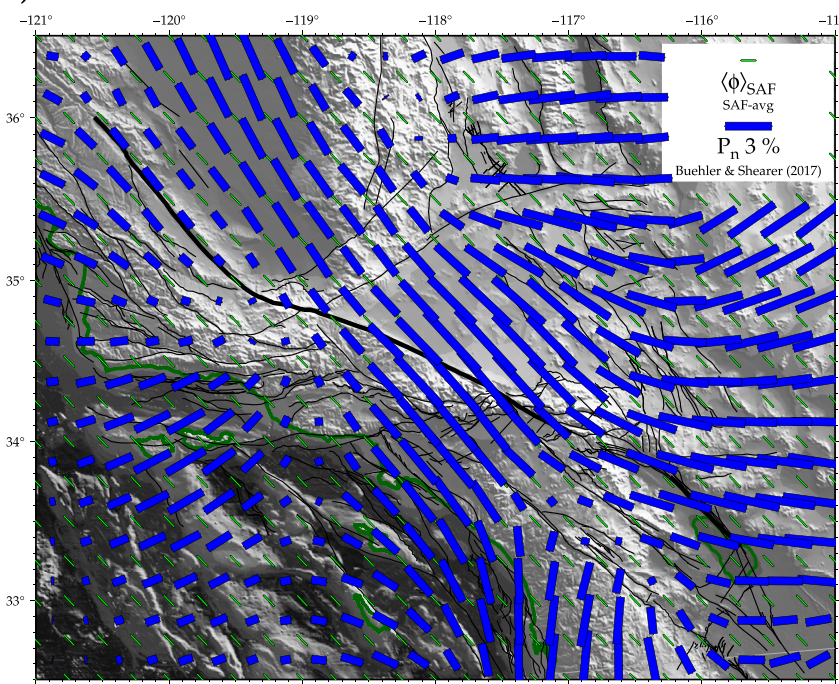

b)

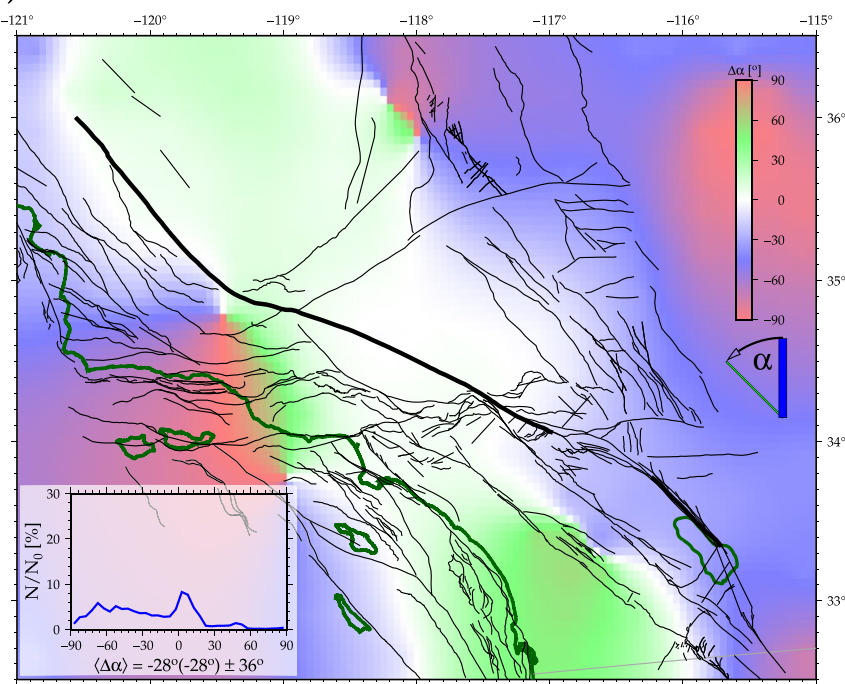

c)

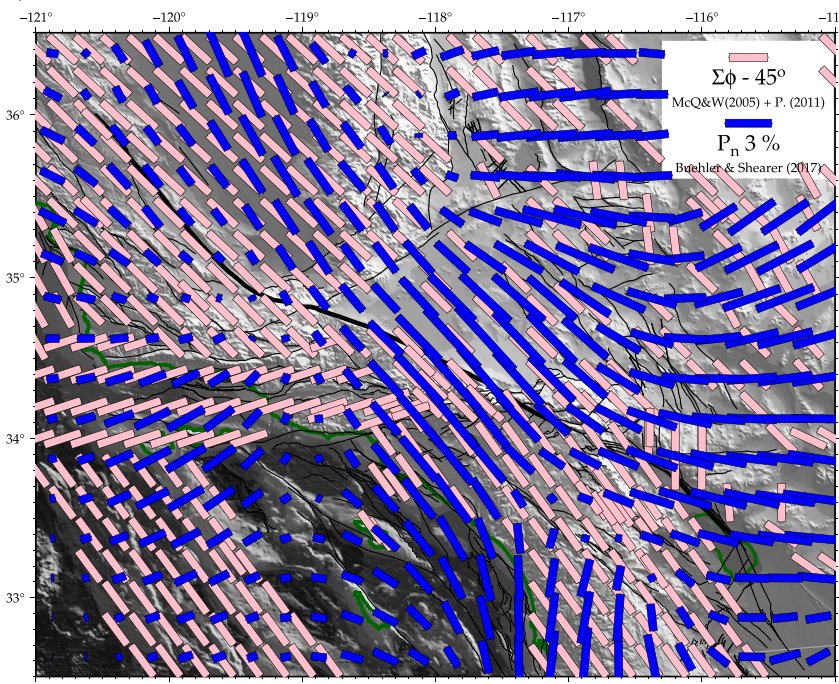

d)

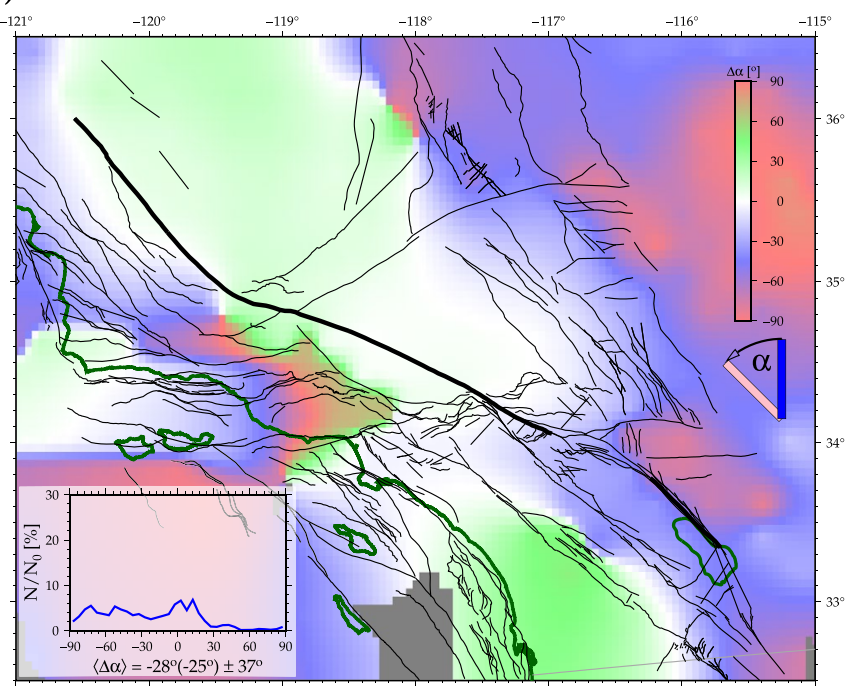

Figure 5. (a) In blue, fast propagation axes and \% anisotropy from $P_{n}$ tomography (Buehler \& Shearer, 2017), compared to San Andreas Fault strike averaged outside of the Big Bend (green bars). (b) Signed angular difference of the quantities in (a), description as for Figure $3 \mathrm{~b}$. (c) $P_{n}$ as in (a), but here compared to Farallon convergence-perpendicular strike including subsequent block rotations from McQuarrie and Wernicke (2005) with interpolated values from Porter et al. (2011). (d) Misorientation for (c), description as in Figure 3b.

ambiguous. The phase of the $A_{1}$ amplitude signal is shown as short one sided arrows in Figure $6 \mathrm{c}$. If the arrival is from the top of an anisotropic layer, then the arrow points in the downdip direction of the dipping foliation below the interface. If the dipping foliation is above the interface, then the arrow would point foliation-updip. These two scenarios assume that the anisotropy is well approximated by a hexagonal slow axis symmetry. The apparent dip sense is reversed if the anisotropy is closer to fast axis hexagonal (Schulte-Pelkum, Ross, et al., 2020). If the conversion is from a dipping contact between isotropic layers, then the phase arrow points downdip for a slow-over-fast dipping shear velocity contrast and reverses sign in the fast-overslow case. The majority of phase arrows point is oriented NE/N/NNW (see also rose histograms in Figure 4 of Schulte-Pelkum, Ross, et al., 2020), consistent with imaging the tops of layers with NE/N/NW-dipping foliation or slow-over-fast isotropic velocity contrasts dipping in the same directions.

We compare the receiver function strikes to Farallon paleofabric (McQuarrie \& Wernicke, 2005; Porter et al., 2011) as for $P_{n}$ in Figures 6a and 6b and to local fault strikes in the SCEC CFM (Plesch et al., 2007) 
a)

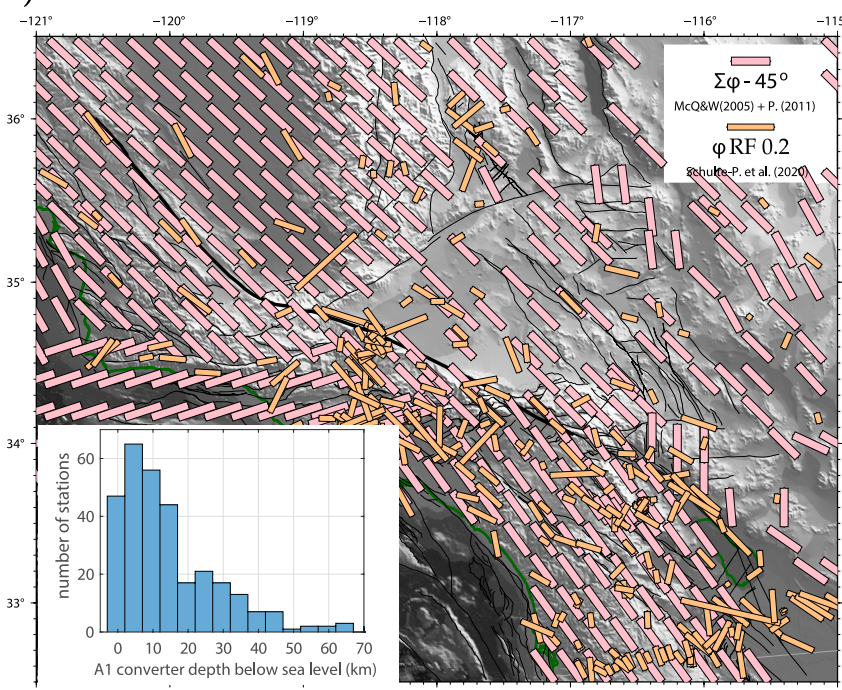

b)

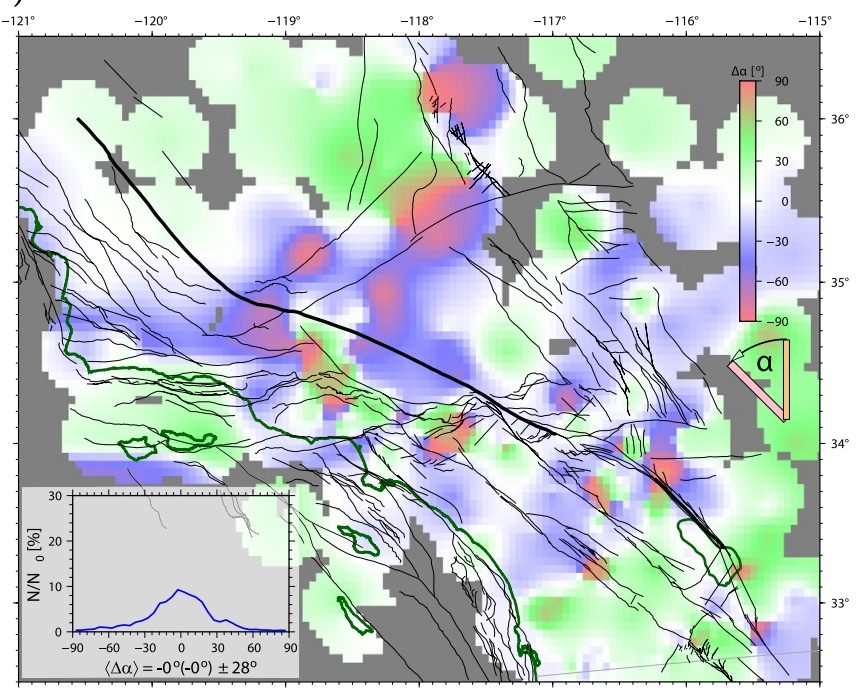

d)

c)

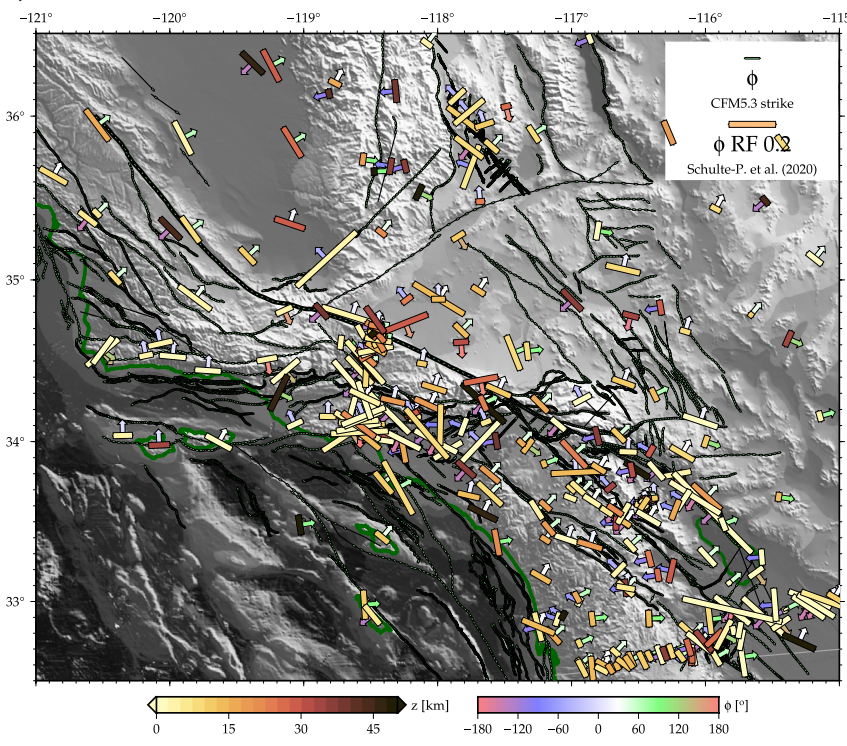

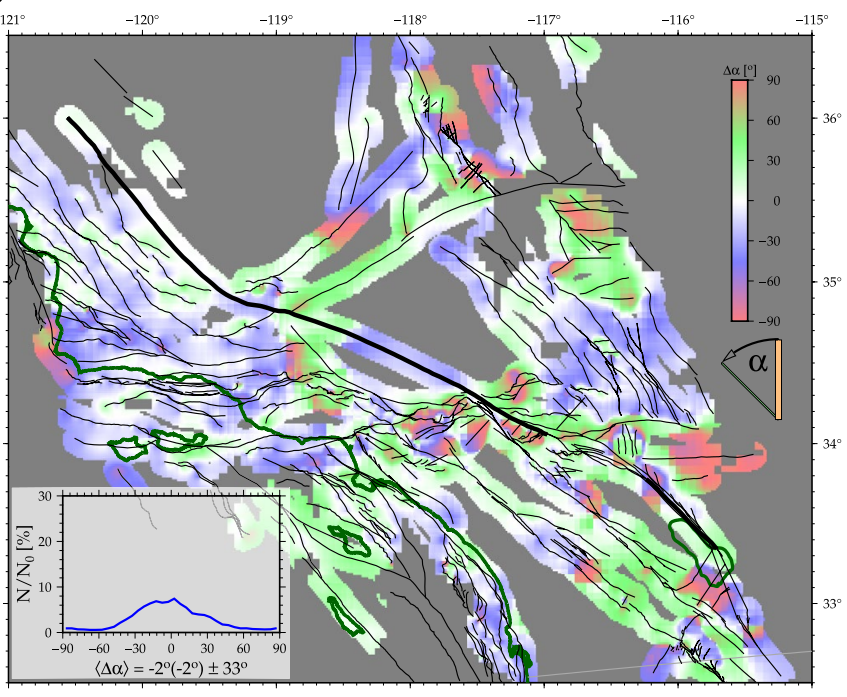

Figure 6. (a) Strikes and amplitude of largest $A_{1}$ harmonic receiver function arrival at each station (in orange), compared to Farallon paleofabric (in pink) as in Figure 5c. Inset shows depth distribution of $A_{1}$ arrivals. (b) Orientation comparison for (a) as in Figure 3b. (c) As in (a), but here compared to local fault strikes from SCEC CFM 5.3 (Plesch et al., 2007) and colored by conversion depth. Short arrows show receiver function inferred up-or downdip direction, colored by the strike of that vector to allow easier geographic subsetting. (d) Orientation comparison for (c).

in Figures $6 \mathrm{c}$ and $6 \mathrm{~d}$. The angular deviation histograms (insets in Figures $6 \mathrm{~b}$ and $6 \mathrm{~d}$ ) are peaked at $0^{\circ}$ and $-2^{\circ}$ deviation, respectively. A rotation of receiver function strikes from SAF-parallel to E-W in the Western Transverse Ranges is matched in both cases. The comparison to Farallon paleofabric shows a higher peak at zero deviation, in part due to station distribution such as the dense Salton Sea experiment (Barak et al., 2015; Klemperer, 2011) showing consistent strikes in the notably presently internally undeformed Peninsular Ranges block near the international border. The comparison to local fault strikes shows reduced scatter such as the improved matches in the northern border of the Western Transverse Ranges and other localized strikes such as the White Wolf Fault (Figure 1). A comparison of receiver function strikes to average SAF strike shows large deviations in the Western Transverse Ranges and in the Eastern California shear zone (Figure 4). Despite the concentration of receiver function strikes above $20 \mathrm{~km}$ depth, there is little 
alignment of the strikes to local event shear wave splitting fast axes (Figure 4), suggesting that microcracks are not a dominant mechanism for generating anisotropy detected by $A_{1}$ arrivals in receiver functions.

As noted in Schulte-Pelkum, Ross, et al. (2020), vertical foliation that may be expected from subvertical shear along transform faults would produce a $180^{\circ}$-periodic arrival with backazimuth $\left(A_{2}\right)$ rather than the $A_{1}$ signal considered here. In our study area, the $A_{2}$ signal amplitude is smaller than that of than $A_{1}$ (Schulte-Pelkum, Ross, et al., 2020). If we assume that Farallon paleofoliations have gentle to intermediate dips and that foliation reset by SAF-age transform motion should be subvertical and possibly concentrated along the SAF, then the strong and geographically distributed $A_{1}$ signal appears to favor paleofabric.

\subsection{Seismogenic Crust and Surface}

As noted, local shear wave splitting is thought to show fast polarization axes parallel to maximum compressive stress due to compression-parallel orientation of microcracks. We compare local $S$ splitting with compressive stress from a focal mechanism inversion (Yang \& Hauksson, 2013) in Figures 7a and 7b. As identified by Z. Li and Peng (2017), there is significant misorientation to the maximum horizontal compressive stress axis along the SAF and other major transform fault strands as well as in additional regions such as the Peninsular and Coast Ranges. In most of these areas of misalignment, local $S$ fast axes are closer to Farallon paleofabric (Figure 6c). In contrast, a comparison of the same focal mechanism-based maximum compressive stress axes with GNSS-derived compressive strain rates (Sandwell et al., 2016) shows a close match, with a strongly peaked distribution centered on $-6^{\circ}$ (Figures $7 \mathrm{c}$ and $7 \mathrm{~d}$ ).

\section{Discussion}

\subsection{Comparing Datasets From all Depths With SAF Transform-Related Stress State}

Figure 8 shows six data sets with progressively deeper depth sensitivities relative to a common, average SAF-based reference orientation for illustration. In this comparison, we use a reference orientation that is rotated $45^{\circ}$ counterclockwise to the SAF average strike. This corresponds to the direction of extension for instantaneous infinitesimal strain on the plate boundary as discussed above. In this figure, we show the unsigned angle difference.

Geodetic inferred deformation and focal mechanism-derived stress orientations agree well with a regional, roughly N-S compressional/E-W extensional state (Figures 7c and 7d). Extensional horizontal strain based on surface geodesy as well as extensional stress from focal mechanisms are roughly E-W, $\sim 45^{\circ}$ counterclockwise from average SAF strike (Figures $8 \mathrm{a}$ and $8 \mathrm{~b}$ ). This is broadly what is expected if the whole region were in a stress and strain-rate state with the major compressive axes oriented N-S and assuming the crust deforms as a viscous continuum. When inferred from focal mechanism inversions, that average azimuthal value is close to $8^{\circ}$ (Yang \& Hauksson, 2013). Surface instantaneous strain as well as focal mechanisms therefore are as expected for the present transform motion, an alignment that is borne out on smaller scales for most faults in the area besides those recently affected by major earthquakes (Becker et al., 2005).

Local shear wave splitting results sample the same depth range as focal mechanisms, but as discussed in Section 2, they have the potential to be parallel to either the compressive stress orientation (in the case of microcracks) and/or the direction of finite strain (in the case of fault gouge fabrics). In some parts of the study area, fast local $S$ splitting polarizations match the focal-mechanism-based stress and GPS-derived strain ( $\sim \mathrm{N}-\mathrm{S}$ fast, parallel to maximum compressive horizontal stress). However, there are significant areas of misorientation along, for example, the SAF and San Jacinto fault and in internally undeformed blocks such as the Peninsular Ranges (Figures 7a and 7b), as discussed by Z. Li and Peng (2017). For these areas of mismatch to the stress field, we hypothesize that shallow splitting observations are dominated by paleofabric (Coastal Ranges, Peninsular Ranges; Figure 6a) and/or present-day fault-parallel (Figure 6c) fabric. Laboratory ultrasonic studies suggest that microcracks in the uppermost crust above crack closure pressure depths may orient themselves along preexisting mineral fabric (Rasolofosaon et al., 2000). We thus propose that shallow splitting of local event shear waves is partly controlled by current stress state, but also partly by rock fabric, some of the latter inherited since it is found to dominate splitting in presently internally non-deforming blocks. 
a)

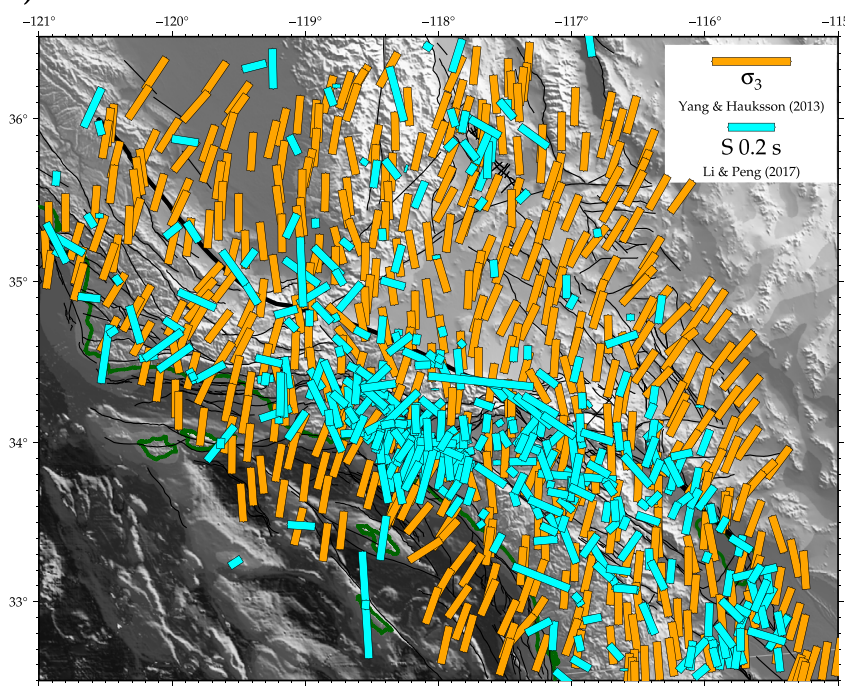

b)

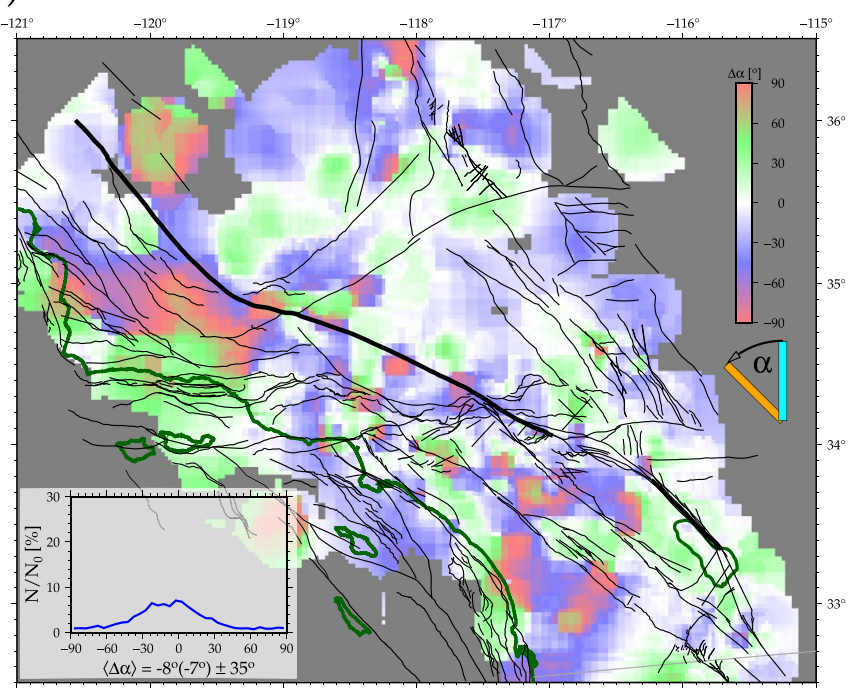

c)

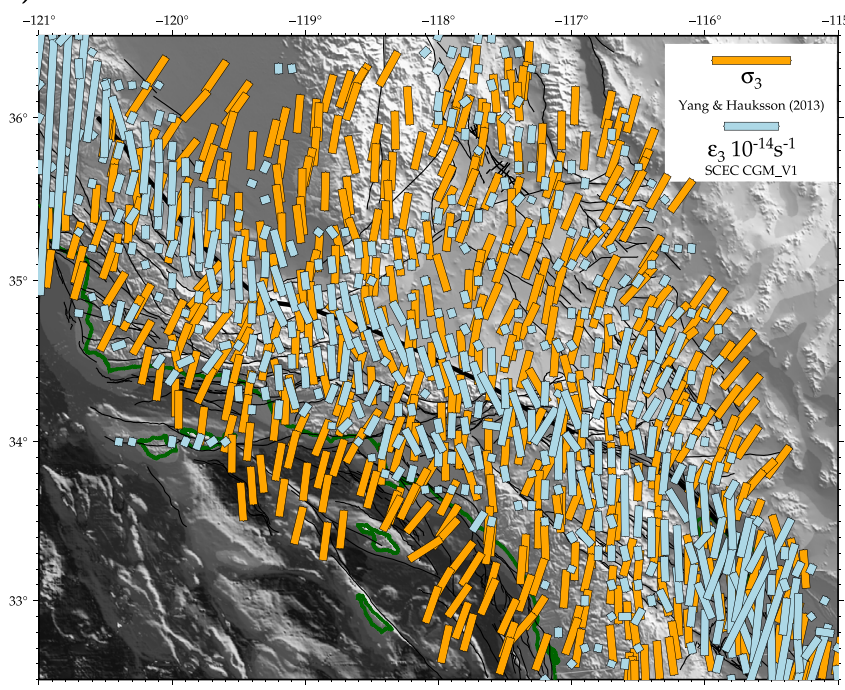

d)

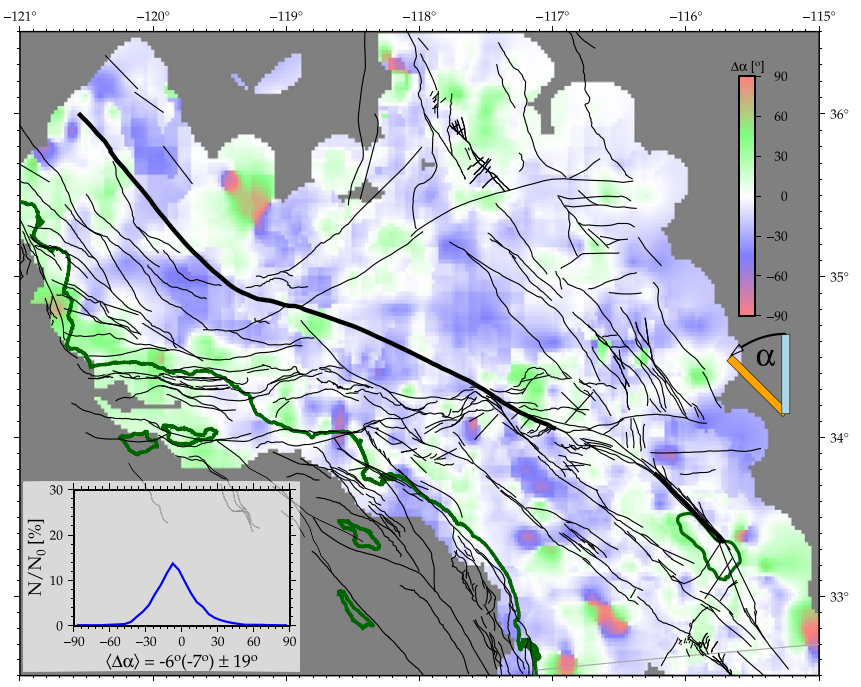

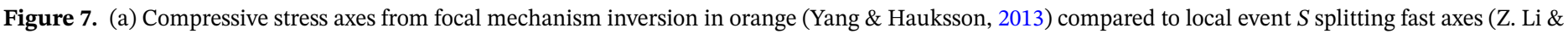

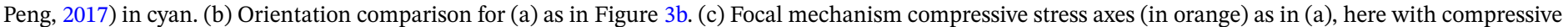

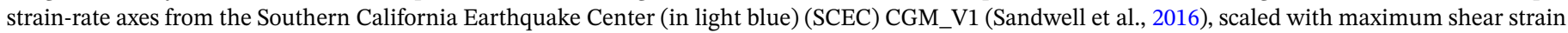
amplitude. (d) Orientation comparison for (c).

Proceeding to the entire crust past seismogenic depths and into the creeping deformation regime, we find that receiver function $A_{1}$ arrivals show a pervasive fabric that deviates from the near-surface E-W extension/N-S compression orientation (Figure 8c), with foliation strikes paralleling present-day surface fault traces as well as paleofabric strikes (Figure 6). It is unlikely that the fabric imaged by receiver functions is strictly due to present-day faulting. Since the inferred fabric is distributed widely geographically (no clear dependence with distance from faults) and in depth, Schulte-Pelkum, Ross, et al. (2020) previously interpreted the receiver function signal as inherited fabric. This conclusion is bolstered by the match between receiver function strikes and paleofabric (Figure 6).

The Moho depth in the study region mostly varies between 25 and $32 \mathrm{~km}$, with a few local Moho roots reaching depths of 35-40 km under the western foothills of the Sierra Nevada, San Bernardino mountains, and Peninsular Ranges (Miller et al., 2014; Ozakin \& Ben-Zion, 2015; Yan \& Clayton, 2007; Zhu \& Kanamori, 2000). Receiver function $A_{1}$ station maxima are concentrated at crustal depths, but reach into 

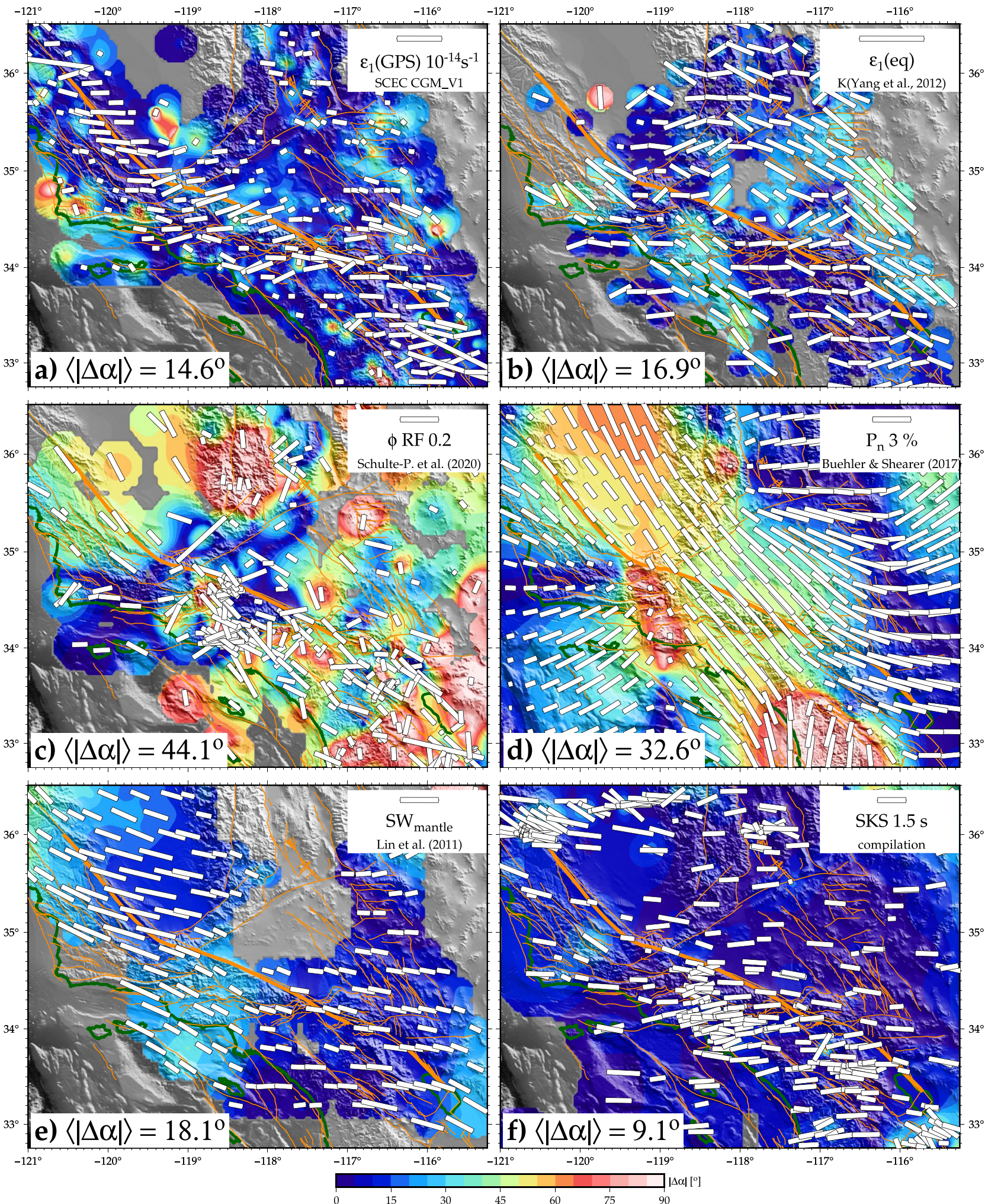

angular deviation from mean SAF strike $-45^{\circ}$

Figure 8. 
lithospheric mantle depths (Figure 6a) with similar strikes to those at shallower depths (Schulte-Pelkum, Ross, et al., 2020). Changes in seismically imaged anisotropic symmetry can be due to changes in mineralogy and do not necessarily imply a change in deformation regime (Bernard \& Behr, 2017; Brownlee et al., 2017), and the converse also holds. Nevertheless, the similarity between receiver function and $P_{n}$ inferred fast strikes (Figure 5) suggests similar fabrics in the deep crust and uppermost lithospheric mantle.

Like receiver functions strikes, $P_{n}$ fast orientations deviate from shallow E-W/N-S orientations (Figure 8d). The area showing SAF-parallel $P_{n}$ fast axes is broad and shows no clear dependence on distance to the SAF. No rotation of $P_{n}$ fast axes are seen in the compressive Big Bend in the Eastern Transverse Ranges. In contrast, the Western Transverse Ranges show $P_{n}$ strikes consistent with compressive Farallon-age paleofabric that was subsequently rotated. This contrast between the western and eastern part of the Big Bend as well as the lack of localization of $P_{n}$ anisotropy relative to major fault strands supports inherited fabric rather than present day deformation as a source of lithospheric mantle fabric. Teleseismic $P$ wave derived anisotropy at $75 \mathrm{~km}$ depth supports this interpretation (Yu \& Zhao, 2018) (Figure 4). Tomographic inversions solving for isotropic and anisotropic structure are in principle subject to trade-off effects between the two types of anomalies. However, the trade-off tests presented in the tomographic studies (Buehler \& Shearer, 2010, 2012, 2014, 2017; Yu \& Zhao, 2018) and the agreement of tomographic $P_{n}$ results with those using azimuthal variations between station pairs (Buehler \& Shearer, 2012; G. P. Smith \& Ekström, 1999) lend some confidence to the results and our interpretation. While isotropic $P_{n}$ velocity models may be impacted by local Moho topography, it is less likely that the fast axes are distorted significantly.

We thus interpret the crustal and lithospheric mantle deformation indicators as a pervasive lithospheric fabric that may largely reflect formation processes (accretion and intrusions during long-lived Farallon subduction) rather than recent deformation processes. Wholesale rotation of fabric at lithospheric mantle depths along with their block surfaces such as in the Western Transverse Ranges and a lack of effects of recent processes such as compression in the Eastern Transverse Ranges on deep crustal and lithospheric mantle fabric suggests that deep fabric is preserved rather than reset.

At deeper levels in the mantle, surface wave tomography and teleseismic splitting show a close correspondence and are not parallel to either paleofabric or SAF strike orientation. SKS fast axes deviate more from SAF strike (Figure 8f) than surface wave fast azimuths at periods sensitive to the mantle (Figure 8e). It is likely that $S K S$ is sensitive to greater depths (asthenosphere) than the surface wave mantle solution (Lin et al., 2011), and the latter may be averaging over lithospheric as well as deeper anisotropy. Although the roughly E-W orientation for $S K S$ matches surface extension (Figure 8a), modeling suggests it is due to asthenospheric broader-scale mantle circulation (Becker, Schulte-Pelkum, et al., 2006). Whether and how this mantle circulation, mostly due to sinking of the formerly subducting slab into the mantle, may control the present-day near-surface stress state remains an open question (Chamberlain et al., 2014; Ghosh et al., 2013; Humphreys \& Coblentz, 2007; Kosarian et al., 2011). Short-wavelength perturbations to SKS likely reflect influence from shallower, lithospheric structure (e.g., Bonnin et al., 2010; Jiang et al., 2018; Savage et al., 2004), but may also be associated to smaller length scale convection than what was considered by Becker, Schulte-Pelkum, et al. (2006) and/or reorientation of olivine fabrics (e.g., Wang \& Becker, 2019; Zhou et al., 2018).

We show histograms of the angular misalignment as in Figures 3-7 for all quantities discussed above as well as additional axial data sets in Figure 9. This comparison is further expanded and summarized in Figure 4 whose quantification of the statistical moments can, however, only incompletely capture the character of alignment where, for example, a block-wise match of orientations can lead to a smeared out distribution (Figure 9). Each comparison pair appears twice in Figure 9, and we show median and standard deviation as well as area of coverage in addition to the angle difference histogram. The quantities compared here are the same as ones discussed above. The comparisons show the same trends of agreement between surface strain and focal mechanism-based sets with deeper mantle estimates from $S K S$ and surface waves on the

Figure 8. Comparison of six data sets in a common reference system. The reference orientation is average San Andreas Fault strike rotated $45^{\circ}$

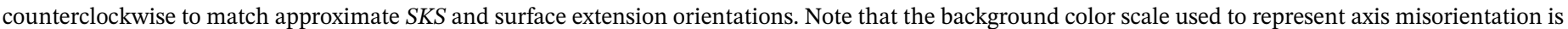

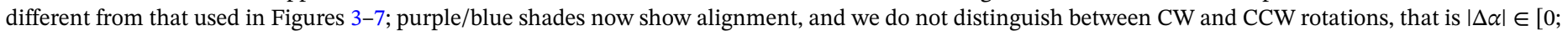

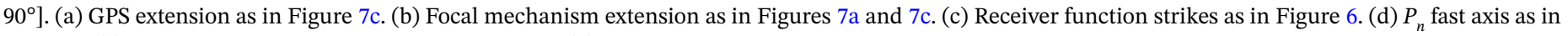
Figure 5. (e) Mantle surface wave fast axis as in Figure 3. (d) $S K S$ fast axes as in Figure 3. 

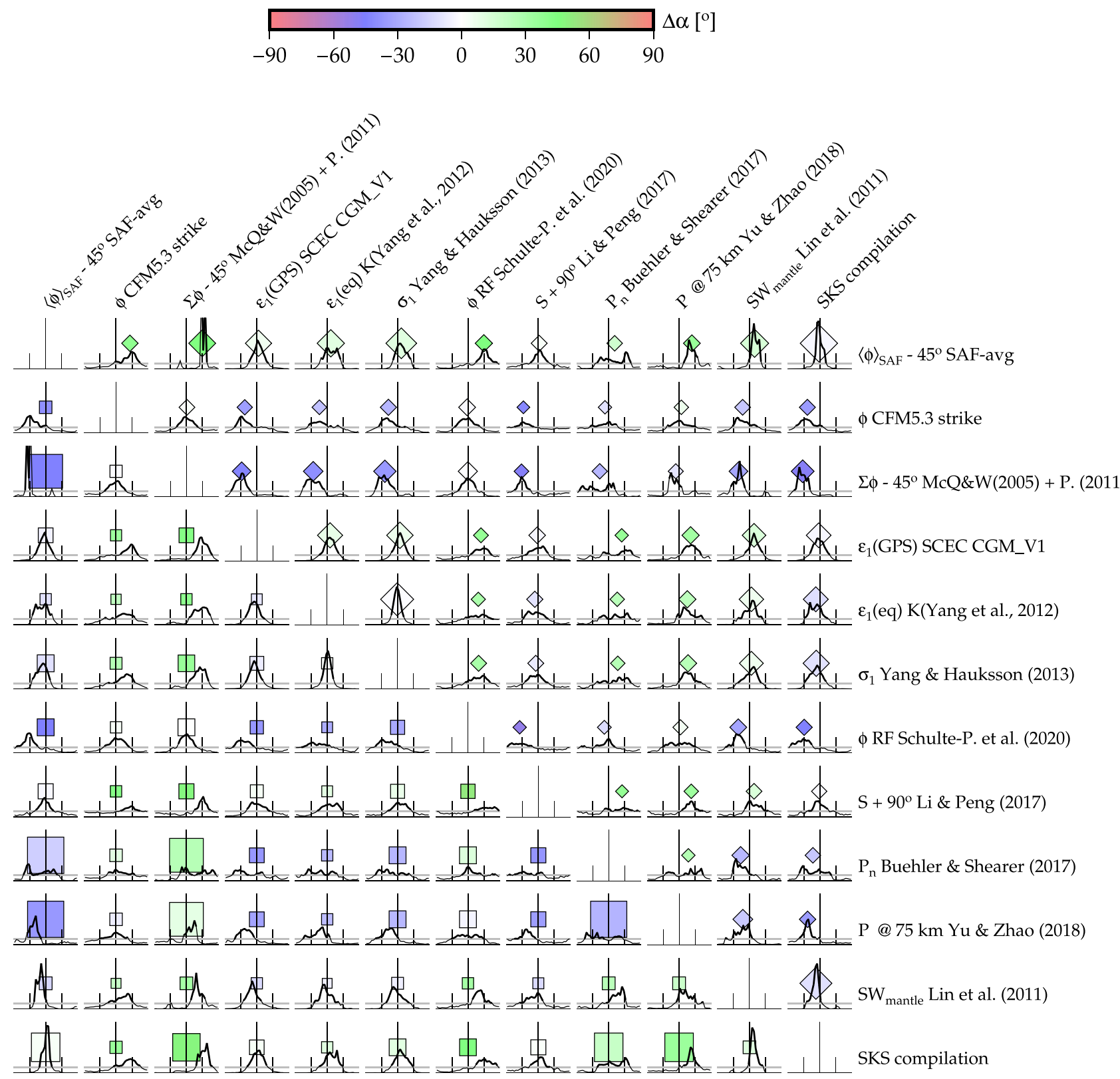

Figure 9. Angular difference histograms $\left(-90 . . .90^{\circ}\right)$ as in for example Figure $3 \mathrm{~b}$ for all data sets discussed above. The top right triangle has as diamonds the median deviation, with the diamond's size scaled with the inverse of the standard deviation and the diamond centered on the median. The lower left has the same coloring, but the square size scales with the area of coverage out of the whole study area. See Figure 4 for a summary representation of an extended comparison set, and Schulte-Pelkum et al. (2021) for cross-comparison plots for all datasets analyzed.

one hand, and between lithospheric estimates (receiver function studies, $P_{n}$, lithospheric depths from $P$ tomography) on the other hand. We conclude that even if mantle strain is transmitted through the lithosphere to the surface, lithospheric fabric itself is preserved from prior tectonics and independent of current lithospheric deformation.

Our interpretation is summarized in Figure 10. Geodetic strain and focal mechanisms are markers of instantaneous strain and match N-S compression and E-W extension oriented at $\sim 45^{\circ}$ to the NW-SE oriented right-lateral relative plate motion. Shallow shear wave splitting results from local events conform to microcracks due to N-W compression in parts of the study region, but show systematic deviations in other areas 


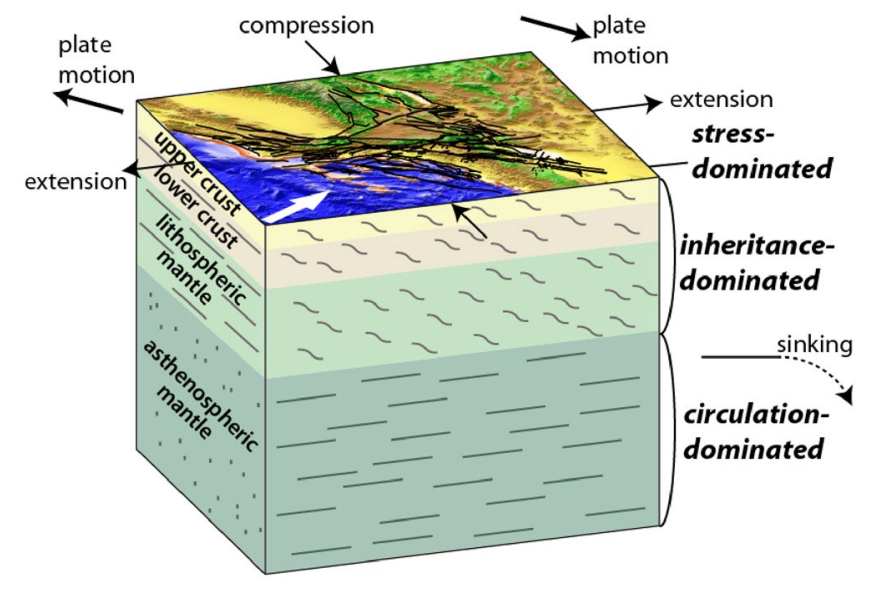

Figure 10. Schematic illustration of dominant mechanisms for strain and seismic anisotropy in the southern California lithosphere and asthenosphere. Only surface strain and focal mechanisms are in accord with compression/extension (black thin arrows) from relative plate motion (black bold arrows). Inherited fabric influences the lithosphere up into the uppermost crust (white arrow is sketched to show approximate orientation of Farallon convergence). Asthenospheric shear reflects large scale circulation with entrainment from a slab sinking far to the east (curved/ dashed arrow). such as near the SAF and in the Coast Ranges and Peninsular Ranges blocks. In the areas of misalignment with stress, the shallow splitting results may be interpreted as fault-parallel (SAF), but they may also show paleofabric, in particular in areas with little present-day internal deformation (Peninsular Ranges block).

\subsection{Potential Origins and Implications of Preserved Paleofabric}

Several lines of evidence support our interpretation that most levels of the crust and lithospheric mantle preserve inherited fabrics as opposed to fabrics that were reset by SAF system deformation. First, although lithospheric orientations are broadly SAF-parallel as well as Farallon paleofabric-parallel, the rotation of these strikes in the Western Transverse Ranges only matches the expected rotations of Farallon paleofabrics and is inconsistent with SAF-related shear. Second, the strength of the receiver function, $P_{n}$, and $P$ signals does not show any obvious dependence with distance from major transform fault strands such as the SAF or San Jacinto fault. Third, azimuthally varying receiver function arrivals from all levels of the crust show strikes that are consistent with dipping foliation. The receiver function signal is not explained by purely vertical or horizontal foliation, but may be caused by foliation dips ranging from subhorizontal $\left(\sim 20^{\circ}\right)$ to steep. The phase of the receiver function signal is consistent with imaging the upper interfaces of anisotropic layers with dominantly NE-dipping fast foliation planes (e.g., schists). If fabric is due to accretionary tectonics and schist underplating during Farallon convergence and subsequent extension, it may be expected to show shallow to intermediate dips (Chapman, 2017; Jacobson et al., 1996). In contrast, most strike-slip faults taking up the present-day transform motion are thought to have intermediate to vertical dips, and foliation from transform shear would be expected to be subvertical. Past receiver function studies in the area that attempted to constrain foliation dip angle (orthogonal to symmetry axis plunge) through waveform modeling inferred a wide range of dips (Audet, 2015; Porter et al., 2011).

While regional-scale surface wave inversions for crustal azimuthal anisotropy are not yet available (Qiu et al., 2019), crustal radial anisotropy shows anomalous negative values (vertically polarized shear wave speeds higher than horizontally polarized shear wave speeds) in the mid-to lower crust, mostly south and west of the SAF (K. Wang et al., 2020). There are several possible explanations for this observation. Steeply dipping schists are one, although K. Wang et al. (2020) argue that the isotropic average velocities in the mid- to lower crust are too high for schists. Another possibility are mafic intrusive dikes. A third possibility is preservation of steep fabrics associated with intrabatholithic strike-slip faults activated during oblique subduction in the Late Cretaceous, as described for several surface exposures in the Sierra Nevada (Busby-Spera \& Saleeby, 1990; Kistler, 1993). Although they seem localized in surface exposures, the receiver function strikes in the southern Sierra Nevada show broad consistency at lower crustal depths (Figure 6c) and are parallel to the Kern Canyon fault (Figure 1), which itself reactivated a Cretaceous ductile shear zone (Busby-Spera \& Saleeby, 1990; Nadin \& Saleeby, 2010). Cretaceous transpressional strike-slip shear zones are also exposed in the eastern San Gabriel mountains within the Transverse Ranges (May \& Walker, 1989).

A fourth option for generation of negative radial anisotropy is suggested by K. Wang et al. (2020) based on xenolith work by Bernard and Behr (2017) showing that feldspars can align with a foliation-perpendicular fast axis. In this case, the lower crust would have high isotropic velocities as well as radial anisotropy. This case would also match the receiver function observations if the foliation is gently dipping, since strikes inferred by the receiver function method are strikes of the plane perpendicular to the symmetry axis, regardless of whether that axis is fast or slow (Brownlee et al., 2017; Schulte-Pelkum \& Mahan, 2014b). Whether foliation is steeply or shallowly dipping, the presence of rotated strikes in the rotated Western Transverse Ranges block compared to dominant NW strikes in the unrotated Central and Eastern Transverse Ranges supports a paleofabric interpretation. Fault strikes themselves match paleofabric strikes well (Figure 4). Reactivation of preexisting structures by faulting is a well-established process (Burchfiel \& Davis, 1975; 
Goodwin \& Wenk, 1995; Nadin \& Saleeby, 2010; Todd et al., 1988), and previous work suggests that inherited mechanical anisotropy and heterogeneity influence current faulting behavior (Barak et al., 2015; Fuis et al., 2017; Langenheim et al., 2004; Schulte-Pelkum, Ross, et al., 2020).

$P_{n}$ sampling the mantle just below the Moho shows fast axes that are broadly parallel to SAF and paleo-subduction strike. Similar results are given for $75 \mathrm{~km}$ depth in anisotropic teleseismic $P$ tomography (Yu \& Zhao, 2018); the neighboring solution grid depths are at 25 and $125 \mathrm{~km}$ depth, and the $75 \mathrm{~km}$ depth slice shows the strongest mantle anisotropy. For $P_{n}$, the prominent NW-SE strike is seen across a broad zone of $\gtrsim 100 \mathrm{~km}$ width through the Big Bend region, showing no obvious change in azimuth along with the SAF. In contrast, $P_{n}$ fast axes are rotated in the Western Transverse Ranges block. This picture is consistent with previously proposed bottom accretion of a stack of Farallon lithospheric mantle slices (Luffi et al., 2009), and/or with strong shearing of North American-affinity mantle in response to flat-slab subduction, as suggested by several studies on western US mantle xenoliths (Behr \& Smith, 2016; Z.-X. A. Li et al., 2008 ; D. Smith et al., 2004; Usui et al., 2003). Similar to receiver functions, the $P_{n}$ orientations appear to support a paleofabric interpretation over SAF motion-induced alignment.

The Transverse Ranges are related to the restraining bend in the SAF, and a number of related mantle anomalies have been proposed previously. A roughly contiguous isotropic Transverse Ranges fast upper mantle anomaly is imaged in body wave tomographic studies (Humphreys \& Dueker, 1994; Schmandt \& Humphreys, 2010; Yu \& Zhao, 2018) and was interpreted as downwelling lithosphere, while surface wave tomography show a fast mantle root limited to the Western (Wang et al., 2018, 2020) or Western and Eastern (Barak et al., 2015) Transverse Ranges. A study that attempted to invert for depth dependent SKS splitting attributed a local patch of E-W fast axes in the Big Bend area to local shortening (Monteiller \& Chevrot, 2011). The downwelling interpretation would be contradicted by the strong azimuthal anisotropy seen in anisotropic $P_{n}$ (Buehler \& Shearer, 2017) and $P$ (Yu \& Zhao, 2018) tomography. It appears difficult to reconcile all tomographic results from the Transverse Ranges area, but the uppermost mantle is also notoriously difficult to resolve.

Irrespective of what the isotropic structure may be, the anisotropic results in conjunction with the crustal receiver function results appear to favor a paleofabric interpretation. One approach to quantify the influence of such paleofabric on present-day deformation, including fault loading, may be via geodynamic modeling of the lithosphere that includes anisotropy of viscosity (i.e., mechanical anisotropy). An early attempt at such an approach was by Ghosh et al. (2013), where the SAF was treated as a weak zone with mechanical anisotropy to explore the links between mantle flow and crustal stress. A smaller-scale extension to lithospheric blocks and analysis of stress and strain markers in our study region seems promising (cf. Mameri et al., 2021).

While it may be tempting to interpret the correspondence between E-W surface extension and E-W SKS splitting fast axes in a pure shear or instantaneous strain framework within SAF-parallel shear, mantle flow modeling studies (Becker, Schulte-Pelkum, et al., 2006; Steinberger, 2000; Wang \& Becker, 2019; Zhou et al., 2018) show that slab sinking to the east of the study area is likely responsible for aligning asthenospheric fabric sampled by teleseismic splitting.

\section{Conclusions}

We compare orientations of stress- and deformation-associated observables such as surface deformation, stress state inverted from focal mechanisms, local event and teleseismic shear wave splitting, receiver function azimuthally varying conversions, $P_{n}$ and local/teleseismic $P$ tomography, and surface wave azimuthal anisotropy, in addition to geological information such as fault strike and block rotations since Farallon subduction. The deformation indicators separate into three classes, with a near-surface match between geodesy and focal mechanisms and some local event shear wave splits, a lithospheric depth range comprising receiver functions, $P_{n}$, and local event splitting in other areas, and an asthenospheric component detected by mantle surface waves and $S K S$ splitting that is driven by mantle circulation and can be speculated to transmit through the lithosphere to drive stress at the surface. Notably, lithospheric rock fabric and anisotropy do not appear to be reset to reflect present-day deformation and instead appear to persist since the time of accretion and intrusion during long-lived subduction. Fabric from the upper crust through the 
lithospheric mantle appears to have been preserved and rotated along with surface block rotations through temporal changes in deformation regimes.

\section{Data Availability Statement}

Data used are from Becker et al. (2012, 2015), Buehler and Shearer (2017), Z. Li and Peng (2017), Lin et al. (2011), McQuarrie and Wernicke (2005), Plesch et al. (2007), Porter et al. (2011), Sandwell et al. (2016), Schulte-Pelkum, Ross, et al. (2020), Yang and Hauksson (2013), Yang et al. (2012), Yu and Zhao (2018).

\section{Acknowledgments}

This analysis was supported by NSF and USGS through SCEC grants 14026, 15059 , and 17097 as well as NSF grants EAR-1927246, EAR-1853856, and EAR1735890. We thank Peter Shearer, Kai Wang, and Chengxin Jiang for discussion, and editor Maureen Long and two anonymous reviewers for comments that helped improve the paper.

\section{References}

Abolfathian, N., Martínez-Garzón, P., \& Ben-Zion, Y. (2020). Variations of stress parameters in the Southern California plate boundary around the South Central Transverse Ranges. Journal of Geophysical Research: Solid Earth, 125, e2020JB019482. https://doi. org/10.1029/2020jb019482

Atwater, T. (1970). Implications of plate tectonics for the Cenozoic tectonic evolution of western North America. Geological Society of America Bulletin, 81, 3513-3536. https://doi.org/10.1130/0016-7606(1970)81(3513:ioptft)2.0.co;2

Atwater, T., \& Stock, J. (1998). Pacific-North America plate tectonics of the Neogene southwestern United States: An update. International Geology Review, 40, 375-402. https://doi.org/10.1080/00206819809465216

Audet, P. (2015). Layered crustal anisotropy around the San Andreas Fault near Parkfield, California. Journal of Geophysical Research: Solid Earth, 120, 3527-3543. https://doi.org/10.1002/2014jb011821

Barak, S., Klemperer, S. L., \& Lawrence, J. F. (2015). San Andreas Fault dip, Peninsular Ranges mafic lower crust and partial melt in the Salton Trough, Southern California, from ambient-noise tomography. Geochemistry, Geophysics, Geosystems, 16, 3946-3972. https://doi. org/10.1002/2015gc005970

Becker, T. W., Chevrot, S., Schulte-Pelkum, V., \& Blackman, D. K. (2006). Statistical properties of seismic anisotropy predicted by upper mantle geodynamic models. Journal of Geophysical Research, 111, B08309. https://doi.org/10.1029/2005JB004095

Becker, T. W., Hardebeck, J. L., \& Anderson, G. (2005). Constraints on fault slip rates of the southern California plate boundary from GPS velocity and stress inversions. Geophysical Journal International, 160, 634-650. https://doi.org/10.1111/j.1365-246x.2004.02528.x

Becker, T. W., Lebedev, S., \& Long, M. D. (2012). On the relationship between azimuthal anisotropy from shear wave splitting and surface wave tomography. Journal of Geophysical Research, 117, B01306. https://doi.org/10.1029/2011JB008705. Original and updated splitting data base retrieved from http://www-udc.ig.utexas.edu/external/becker/sksdata.html

Becker, T. W., Schaeffer, A. J., Lebedev, S., \& Conrad, S. P. (2015). Toward a generalized plate motion reference frame. Geophysical Research Letters, 42, 3188-3196. https://doi.org/10.1002/2015GL063695

Becker, T. W., Schulte-Pelkum, V., Blackman, D. K., Kellogg, J. B., \& O'Connell, R. J. (2006). Mantle flow under the western United States from shear wave splitting. Earth and Planetary Science Letters, 247, 235-251. https://doi.org/10.1016/j.epsl.2006.05.010

Behr, W. M., \& Smith, D. (2016). Deformation in the mantle wedge associated with Laramide flat-slab subduction. Geochemistry, Geophysics, Geosystems, 17(7), 2643-2660. https://doi.org/10.1002/2016gc006361

Bennett, R. A., Rodi, W., \& Reilinger, R. E. (1996). Global Positioning System constraints on fault slip rates in southern California and northern Baja. Journal of Geophysical Research, 101, 21943-21960. https://doi.org/10.1029/96jb02488

Bernard, R. E., \& Behr, W. M. (2017). Fabric heterogeneity in the Mojave lower crust and lithospheric mantle in Southern California. Journal of Geophysical Research: Solid Earth, 122, 5000-5025. https://doi.org/10.1002/2017jb014280

Bianchi, I., Park, J., Agostinetti, N. P., \& Levin, V. (2010). Mapping seismic anisotropy using harmonic decomposition of receiver functions: An application to Northern Apennines, Italy. Journal of Geophysical Research, 115, B12317. https://doi.org/10.1029/2009JB007061

Bird, P. (2003). An updated digital model of plate boundaries. Geochemistry, Geophysics, Geosystems, 4(3), 1027. https://doi. org/10.1029/2001GC000252

Bokelmann, G. H. R. (2002). Convection-driven motion of the North American craton: Evidence from P-wave anisotropy. Geophysical Journal International, 148, 278-287. https://doi.org/10.1046/j.1365-246x.2002.01008.x

Boness, N. L., \& Zoback, M. D. (2006). Mapping stress and structurally controlled crustal shear velocity anisotropy in California. Geology, 34, 825-828. https://doi.org/10.1130/g22309.1

Bonnin, M., Barruol, G., \& Bokelmann, G. H. (2010). Upper mantle deformation beneath the North American-Pacific plate boundary in California from SKS splitting. Journal of Geophysical Research, 115(B4), B04306. https://doi.org/10.1029/2009jb006438

Bourne, S. J., England, P. C., \& Parsons, B. (1998). The motion of crustal blocks driven by flow of the lower lithosphere and implications for slip rates of continental strike-slip faults. Nature, 391, 655-659. https://doi.org/10.1038/35556

Brownlee, S. J., Schulte-Pelkum, V., Raju, A., Mahan, K., Condit, C., \& Orlandini, O. F. (2017). Characteristics of deep crustal seismic anisotropy from a compilation of rock elasticity tensors and their expression in receiver functions. Tectonics, 36, 1835-1857. https://doi. org/10.1002/2017TC004625

Buehler, J. S., \& Shearer, P. (2014). Anisotropy and Vp/Vs in the uppermost mantle beneath the western United States from joint analysis of Pn and Sn phases. Journal of Geophysical Research, 119, 1200-1219. https://doi.org/10.1002/2013jb010559

Buehler, J. S., \& Shearer, P. M. (2010). Pn tomography of the western United States using US Array. Journal of Geophysical Research, 115, B09315. https://doi.org/10.1029/2009JB006874

Buehler, J. S., \& Shearer, P. M. (2012). Localized imaging of the uppermost mantle with USArray Pn data. Journal of Geophysical Research, 117, B09305. https://doi.org/10.1029/2012JB009433

Buehler, J. S., \& Shearer, P. M. (2017). Uppermost mantle seismic velocity structure beneath USArray. Journal of Geophysical Research: Solid Earth, 122, 436-448. https://doi.org/10.1002/2016JB013265

Burchfiel, B., \& Davis, G. (1975). Nature and controls of Cordilleran orogenesis, western United-States - Extensions of an earlier synthesis. American Journal of Science, A275, 363-396.

Busby-Spera, C. J., \& Saleeby, J. B. (1990). Intra-arc strike-slip fault exposed at batholithic levels in the southern Sierra Nevada, California. Geology, 18(3), 255-259. https://doi.org/10.1130/0091-7613(1990)018<0255:iassfe >2.3.co;2 
Bystricky, M., Kunze, K., Burlini, L., \& Burg, J.-P. (2000). High shear strain of olivine aggregates: Rheological and seismic consequences. Science, 290, 1564-1567. https://doi.org/10.1126/science.290.5496.1564

Castelnau, O., Blackman, D. K., \& Becker, T. W. (2009). Numerical simulations of texture development and associated rheological anisotropy in regions of complex mantle flow. Geophysical Research Letters, 36, L12304. https://doi.org/10.1029/2009GL038027

Chamberlain, C., Houlié, N., Bentham, H., \& Stern, T. (2014). Lithosphere-asthenosphere interactions near the San Andreas Fault. Earth and Planetary Science Letters, 399, 14-20. https://doi.org/10.1016/j.epsl.2014.04.048

Chapman, A. D. (2017). The Pelona-Orocopia-Rand and related schists of southern California: A review of the best-known archive of shallow subduction on the planet. International Geology Review, 59, 664-701. https://doi.org/10.1080/00206814.2016.1230836

Chuang, R. Y., \& Johnson, K. (2011). Reconciling geologic and geodetic model fault slip-rate discrepancies in Southern California: Consideration of nonsteady mantle flow and lower crustal fault creep. Geology, 39, 627-630. https://doi.org/10.1130/g32120.1

Crampin, S., \& Chastin, S. (2003). A review of shear wave splitting in the crack-critical crust. Geophysical Journal International, 155, 221-240. https://doi.org/10.1046/j.1365-246x.2003.02037.x

Dickinson, W. R. (1970). Relations of andesites, granites, and derivative sandstones to arc-trench tectonics. Reviews of Geophysics, 8(4), 813-860. https://doi.org/10.1029/rg008i004p00813

Ernst, W. G. (1970). Tectonic contact between the Franciscan mélange and the Great Valley sequence—Crustal expression of a late Mesozoic Benioff zone. Journal of Geophysical Research, 75(5), 886-901. https://doi.org/10.1029/jb075i005p00886

Flesch, L. M., Holt, W. E., Haines, A. J., \& Shen-Tu, B. (2000). Dynamics of the Pacific-North American plate boundary in the western United States. Science, 287, 834-836. https://doi.org/10.1126/science.287.5454.834

Fuis, G. S., Bauer, K., Goldman, M. R., Ryberg, T., Langenheim, V. E., Scheirer, D. S., \& Aagaard, B. (2017). Subsurface geometry of the San Andreas Fault in Southern California: Results from the Salton Seismic Imaging Project (SSIP) and strong ground motion expectations. Bulletin of the Seismological Society of America, 107, 1642-1662. https://doi.org/10.1785/0120160309

Gephart, J. W., \& Forsyth, D. W. (1984). An improved method for determining the regional stress tensor using earthquake focal mechanism data: Application to the San Fernando earthquake sequence. Journal of Geophysical Research, 89, 9305-9320. https://doi.org/10.1029/ jb089ib11p09305

Ghosh, A., Becker, T. W., \& Humphreys, E. D. (2013). Dynamics of the North American continent. Geophysical Journal International, 194, 651-669. https://doi.org/10.1093/gii/ggt151

Goodwin, L., \& Wenk, H. (1995). Development of phyllonite from granodiorite - Mechanisms of grain-size reduction in the Santa-Rosa mylonite zone, California. Journal of Structural Geology, 17, 689-707. https://doi.org/10.1016/0191-8141(94)00093-f

Haines, A. J., Dimitrova, L. L., Wallace, L. M., \& Williams, C. A. (2015). Enhanced surface imaging of crustal deformation: Obtaining tectonic force fields using GPS data. Springer.

Haines, A. J., \& Holt, W. E. (1993). A procedure to obtain the complete horizontal motions within zones of distributed deformation from the inversion of strain rate data. Journal of Geophysical Research, 98, 12057-12082. https://doi.org/10.1029/93jb00892

Hamilton, W. (1969). Mesozoic California and the underflow of Pacific mantle. Geological Society of America Bulletin, 80(12), 2409-2430. https://doi.org/10.1130/0016-7606(1969)80(2409:mcatuo)2.0.co;2

Hansen, L. N., Zhao, Y.-H., Zimmerman, M. E., \& Kohlstedt, D. L. (2014). Protracted fabric evolution in olivine: Implications for the relationship among strain, crystallographic fabric, and seismic anisotropy. Earth and Planetary Science Letters, 387, 157-168. https://doi. org/10.1016/j.epsl.2013.11.009

Hardebeck, J. L., \& Michael, A. J. (2004). Stress orientations at intermediate angles to the San Andreas Fault, California. Journal of Geophysical Research, 109, B11303. https://doi.org/10.1029/2004JB003239

Hardebeck, J. L., \& Michael, A. J. (2006). Damped regional-scale stress inversions: Methodology and examples for southern California and the Coalinga aftershock sequence. Journal of Geophysical Research, 111, B11310. https://doi.org/10.1029/2005JB004144

Hartog, R., \& Schwartz, S. Y. (2001). Depth-dependent mantle anisotropy below the San Andreas fault system: Apparent splitting parameters and waveforms. Journal of Geophysical Research, 106, 4155-4167. https://doi.org/10.1029/2000jb900382

Hearn, E. H. (2019). Kinematics of southern California crustal deformation: Insights from finite-element models. Tectonophysics, 758, 12-28. https://doi.org/10.1016/j.tecto.2019.02.016

Hearn, E. H., Pollitz, F. F., Thatcher, W. R., \& Onishi, C. T. (2013). How do "ghost transients" from past earthquakes affect GPS slip rate estimates on southern California faults? Geochemistry, Geophysics, Geosystems, 14(4), 828-838. https://doi.org/10.1002/ggge.20080

Hearn, T. M. (1996). Anisotropic $P_{n}$ tomography in the western United States. Journal of Geophysical Research, 101, 8403-8414. https:// doi.org/10.1029/96jb00114

Hetland, E. A., \& Hager, B. H. (2006). Interseismic strain accumulation: Spin-up, cycle invariance, and irregular rupture sequences. Geochemistry, Geophysics, Geosystems, 7(5), Q05004. https://doi.org/10.1029/2005gc001087

Humphreys, E. D., \& Coblentz, D. (2007). North American dynamics and western U.S. tectonics. Reviews of Geophysics, 45, RG3001. https://doi.org/10.1029/2005RG000181

Humphreys, E. D., \& Dueker, K. G. (1994). Western U.S. upper mantle structure. Journal of Geophysical Research, 99, 9615-9634. https:// doi.org/10.1029/93jb01724

Jacobson, C. E., Oyarzabal, F. R., \& Haxel, G. B. (1996). Subduction and exhumation of the Pelona-Orocopia-Rand schists, southern California. Geology, 24(6), 547-550. https://doi.org/10.1130/0091-7613(1996)024<0547:saeotp>2.3.co;2

Jiang, C., Schmandt, B., \& Clayton, R. W. (2018). An anisotropic contrast in the lithosphere across the Central San Andreas Fault. Geophysical Research Letters, 45, 3967-3975. https://doi.org/10.1029/2018gl077476

Kaviani, A., Rümpker, G., Weber, M., \& Asch, G. (2011). Short-scale variations of shear-wave splitting across the Dead Sea basin: Evidence for the effects of sedimentary fill. Geophysical Research Letters, 38(4), L04308. https://doi.org/10.1029/2010GL046464

Kistler, R. W. (1993). Mesozoic intrabatholithic faulting, Sierra Nevada, California. In K. A. Dunne George C, \& McDougall (Eds.), Field trip guidebook - Pacific section, Society of Economic Paleontologists and Mineralogists (Vol. 71, pp. 247-261). Pacific Section SEPM.

Klemperer, S. (2011). Passive seismic study of a magma-dominated rift: The Salton trough. International Federation of Digital Seismograph Networks. https://doi.org/10.7914/SN/XD_2011

Kosarian, M., Davis, P., Tanimoto, T., \& Clayton, R. (2011). The relationship between upper mantle anisotropic structures beneath California, transpression, and absolute plate motions. Journal of Geophysical Research, 116, B08307. https://doi.org/10.1029/2010JB007742

Kostrov, B. V. (1974). Seismic moment and energy of earthquakes and seismic flow of rock. Physics of the Solid Earth, 1, 23-40.

Kreemer, C., Blewitt, G., \& Klein, E. C. (2014). A geodetic plate motion and Global Strain Rate Model. Geochemistry, Geophysics, Geosystems, 15, 3849-3889. https://doi.org/10.1002/2014GC005407

Kreemer, C., Haines, J., Holt, W. E., Blewitt, G., \& Lavallée, D. (2000). On the determination of a global strain rate model. Earth Planets and Space, 52, 765-770. https://doi.org/10.1186/bf03352279 
Langenheim, V., Jachens, R., Morton, D., Kistler, R., \& Matti, J. (2004). Geophysical and isotopic mapping of preexisting crustal structures that influenced the location and development of the San Jacinto fault zone, southern California. Geological Society of America Bulletin, 116, 1143-1157. https://doi.org/10.1130/b25277.1

Lekic, V., Fischer, K. M., \& French, S. (2011). Lithospheric thinning beneath rifted regions of Southern California. Science, 334, 783-787. https://doi.org/10.1126/science.1208898

Levander, A., \& Miller, M. S. (2012). Evolutionary aspects of the lithosphere discontinuity structure in the western U.S. Geochemistry, Geophysics, Geosystems, 13, Q0AK07. https://doi.org/10.1029/2012GC004056

Levin, V., \& Park, J. (1998). P - SH conversions in layered media with hexagonally symmetric anisotropy: A cookbook. Pure and Applied Geophysics, 151, 669-697. https://doi.org/10.1007/978-3-0348-8777-9_25

Li, Z., \& Peng, Z. (2017). Stress- and structure-induced anisotropy in Southern California from two decades of shear wave splitting measurements. Geophysical Research Letters, 44, 9607-9614. https://doi.org/10.1002/2017GL075163

Li, Z.-X. A., Lee, C.-T. A., Peslier, A. H., Lenardic, A., \& Mackwell, S. J. (2008). Water contents in mantle xenoliths from the Colorado Plateau and vicinity: Implications for the mantle rheology and hydration-induced thinning of continental lithosphere. Journal of Geophysical Research, 113(B9), B09210. https://doi.org/10.1029/2007jb005540

Lin, F. C., Ritzwoller, M. H., Yang, Y., Moschetti, M. P., \& Fouch, M. J. (2011). Complex and variable crustal and uppermost mantle seismic anisotropy in the western United States. Nature Geoscience, 4, 55-61. https://doi.org/10.1038/ngeo1036

Liu, Z., \& Park, J. (2017). Seismic receiver function interpretation: Ps splitting or anisotropic underplating? Geophysical Journal International, 208, 1332-1341. https://doi.org/10.1093/gji/ggw455

Luffi, P., Saleeby, J. B., Lee, C.-T. A., \& Ducea, M. N. (2009). Lithospheric mantle duplex beneath the central Mojave Desert revealed by xenoliths from Dish Hill, California. Journal of Geophysical Research, 114, B03202. https://doi.org/10.1029/2008JB005906

Luttrell, K., \& Hardebeck, J. (2021). A unified model of crustal stress heterogeneity from borehole breakouts and earthquake focal mechanisms. Journal of Geophysical Research: Solid Earth, 126(2), e2020JB020817. https://doi.org/10.1029/2020JB020817

Mameri, L., Tommasi, A., Signorelli, J., \& Hassani, R. (2021). Olivine-induced viscous anisotropy in fossil strike-slip mantle shear zones and associated strain localization in the crust. Geophysical Journal International, 224, 608-625.

Matti, J. C., Morton, D. M., \& Cox, B. F. (1992). The San Andreas fault system in the vicinity of the central Transverse Ranges province, southern California (Vol. 92). US Geological Survey.

Matti, J. C., Morton, D. M., Powell, R., \& Weldon, R. (1993). Paleogeographic evolution of the San Andreas fault in southern California: A reconstruction based on a new cross-fault correlation. The San Andreas fault system: Displacement, palinspastic reconstruction, and geologic evolution, 178, 107-160. https://doi.org/10.1130/mem178-p107

May, D. J., \& Walker, N. W. (1989). Late Cretaceous juxtaposition of metamorphic terranes in the southeastern San Gabriel Mountains, California. Geological Society of America Bulletin, 101(10), 1246-1267. https://doi.org/10.1130/0016-7606(1989)101<1246:lcjomt>2.3.co;2

McKenzie, D. P. (1969). The relation between fault plane solutions for earthquakes and the directions of the principal stresses. Bulletin of the Seismological Society of America, 59, 591-601. https://doi.org/10.1785/bssa0590020591

McKenzie, D. P., \& Jackson, J. (1983). The relationship between strain rates, crustal thickening, paleomagnetism, finite strain and fault movements within a deforming zone. Earth and Planetary Science Letters, 65, 182-202. https://doi.org/10.1016/0012-821x(83)90198-x

McQuarrie, N., \& Wernicke, B. P. (2005). An animated tectonic reconstruction of southwestern North America since 36 Ma. Geosphere, 1, 147-172. https://doi.org/10.1130/ges00016.1

Meade, B. J., \& Hager, B. H. (2005). Block models of crustal motion in southern California constrained by GPS measurements. Journal of Geophysical Research, 110, B03403. https://doi.org/10.1029/2004JB003209

Michael, A. J. (1984). Determination of stress from slip data; faults and folds. Journal of Geophysical Research, 89, 11517-11526. https:// doi.org/10.1029/jb089ib13p11517

Miller, M. S., Zhang, P., \& Dolan, J. (2014). Moho structure across the San Jacinto fault zone: Insights into strain localization at depth. Lithosphere, 6, 43-47. https://doi.org/10.1130/1295.1

Monteiller, V., \& Chevrot, S. (2011). High-resolution imaging of the deep anisotropic structure of the San Andreas Fault system beneath southern California. Geophysical Journal International, 182, 418-446. https://doi.org/10.1111/j.1365-246x.2011.05082.x

Nadin, E. S., \& Saleeby, J. B. (2010). Quaternary reactivation of the Kern Canyon fault system, southern Sierra Nevada, California. Geological Society of America Bulletin, 122, 1671-1685. https://doi.org/10.1130/b30009.1

Nicholson, C., Sorlien, C., Atwater, T., Crowell, J., \& Luyendyk, B. (1994). Microplate capture, rotation of the Western Transverse Ranges, and initiation of the San-Andreas transform as a low-angle fault system. Geology, 22, 491-495. https://doi. org/10.1130/0091-7613(1994)022<0491:mcrotw>2.3.co;2

Ozakin, Y., \& Ben-Zion, Y. (2015). Systematic receiver function analysis of the Moho geometry in the southern California plate-boundary region. Pure and Applied Geophysics, 172, 1167-1184. https://doi.org/10.1007/s00024-014-0924-6

Özalaybey, S., \& Savage, M. K. (1995). Shear-wave splitting beneath western United States in relation to plate tectonics. Journal of Geophysical Research, 100, 18135-18149. https://doi.org/10.1029/95jb00715

Park, J., \& Levin, V. (2016). Anisotropic shear zones revealed by backazimuthal harmonics of teleseismic receiver functions. Geophysical Journal International, 207, 1216-1243. https://doi.org/10.1093/gii/ggw323

Persaud, P., Pritchard, E. H., \& Stock, J. M. (2020). Scales of stress heterogeneity near active faults in the Santa Barbara Channel, southern California. Geochemistry, Geophysics, Geosystems, 21(1), e2019GC008744. https://doi.org/10.1029/2019gc008744

Plesch, A., Shaw, J. H., Benson, C., Bryant, W. A., Carena, S., Cooke, M., et al. (2007). Community fault model (CFM) for southern California. Bulletin of the Seismological Society of America, 97, 1793-1802. https://doi.org/10.1785/0120050211

Polet, J., \& Kanamori, H. (2002). Anisotropy beneath California: Shear wave splitting measurements using a dense broadband array. Geophysical Journal International, 149, 313-327. https://doi.org/10.1046/j.1365-246x.2002.01630.x

Pollard, D. D., Saltzer, S. D., \& Rubin, A. (1993). Stress inversion methods: Are they based on faulty assumptions? Journal of Structural Geology, 15, 1045-1054. https://doi.org/10.1016/0191-8141(93)90176-b

Porter, R., Zandt, G., \& McQuarrie, N. (2011). Pervasive lower-crustal seismic anisotropy in Southern California: Evidence for underplated schists and active tectonics. Lithosphere, 3, 201-220. https://doi.org/10.1130/L126.1

Qiu, H., Lin, F.-C., \& Ben-Zion, Y. (2019). Eikonal tomography of the Southern California plate boundary region. Journal of Geophysical Research: Solid Earth, 124, 9755-9779. https://doi.org/10.1029/2019JB017806

Ramsay, J., Kohler, M. D., Davis, P. M., Wang, X., Holt, W., \& Weeraratne, D. S. (2016). Anisotropy from SKS splitting across the Pacific-North America plate boundary offshore southern California. Geophysical Journal International, 207, $244-258$. https://doi.org/10.1093/gii/ggw271 
Rasolofosaon, P., Rabbel, W., Siegesmund, S., \& Vollbrecht, A. (2000). Characterization of crack distribution: Fabric analysis versus ultrasonic inversion. Geophysical Journal International, 141, 413-424. https://doi.org/10.1046/j.1365-246x.2000.00093.x

Sandwell, D. T., Becker, T. W., Bird, P., Fialko, Y., Freed, A., Holt, W. E., \& Zeng, Y. (2009). Comparison of strain-rate maps of western North America. Southern California earthquake center annual meeting. Proceedings and Abstracts, 19, 278. Retrieved from www.scec.org/ meetings/2009am/2009SCECAnnualMeetingVolume.pdf

Sandwell, D. T., \& Wessel, P. (2016). Interpolation of 2-D vector data using constraints from elasticity. Geophysical Research Letters, 43, 10703-10709. https://doi.org/10.1002/2016gl070340

Sandwell, D. T., Zeng, Y., Shen, Z.-K., Crowell, B., Murray, J., McCaffrey, R., \& Xu, X. (2016). The SCEC community geodetic model V1: Horizontal velocity grid. Tech. Rep. Scripps Institution of Oceanography, UCSD. Retrieved from http://topex.ucsd.edu/CGM/ technical_report/CGM_V1.pdf

Savage, M. K., Fischer, K. M., \& Hall, C. E. (2004). Strain modelling, seismic anisotropy and coupling at strike-slip boundaries: Applications in New Zealand and the San Andreas fault. In J. Grocott, B. Tikoff, K. J. W. McCaffrey, \& G. Taylor (Eds.), Vertical coupling and decoupling in the lithosphere (Vol. 227, pp. 9-39). Geological Society of London. https://doi.org/10.1144/gsl.sp.2004.227.01.02

Savage, M. K., \& Sheehan, A. F. (2000). Seismic anisotropy and mantle flow from the Great Basin to the Great Plains, western United States. Journal of Geophysical Research, 105, 13715-13734. https://doi.org/10.1029/2000jb900021

Savage, M. K., \& Silver, P. G. (1993). Mantle deformation and tectonics: Constraints from seismic anisotropy in the western United States. Physics of the Earth and Planetary Interiors, 78, 207-227. https://doi.org/10.1016/0031-9201(93)90156-4

Schmandt, B., \& Humphreys, E. (2010). Seismic heterogeneity and small-scale convection in the southern California upper mantle. Geochemistry, Geophysics, Geosystems, 11, Q05004. https://doi.org/10.1029/2010GC003042

Schulte-Pelkum, V., Becker, T. W., Behr, W. M., \& Miller, M. S. (2021). Supplementary material for Tectonic inheritance during plate boundary evolution in southern California constrained from seismic anisotropy. Figshare. https://doi.org/10.6084/m9.figshare.16840618.v1

Schulte-Pelkum, V., Caine, J. S., Jones, J. V. I., \& Becker, T. W. (2020). Imaging the tectonic grain of the Northern Cordillera orogen using Transportable Array receiver functions. Seismological Research Letters, 91(6), 3086-3105. https://doi.org/10.1785/0220200182

Schulte-Pelkum, V., \& Mahan, K. H. (2014a). Imaging faults and shear zones using receiver functions. Pure and Applied Geophysics, 171, 2967-2991. https://doi.org/10.1007/s00024-014-0853-4

Schulte-Pelkum, V., \& Mahan, K. H. (2014b). A method for mapping crustal deformation and anisotropy with receiver functions and first results from USArray. Earth and Planetary Science Letters, 402, 221-233. https://doi.org/10.1016/j.epsl.2014.01.050

Schulte-Pelkum, V., Ross, Z. E., Mueller, K., \& Ben-Zion, Y. (2020). Tectonic inheritance with dipping faults and deformation fabric in the brittle and ductile southern California crust. Journal of Geophysical Research: Solid Earth, 125(8), e2020JB019525. https://doi. org/10.1029/2020JB019525

Silver, P. G. (1996). Seismic anisotropy beneath the continents: Probing the depths of geology. Annual Review of Earth and Planetary Sciences, 24, 385-432. https://doi.org/10.1146/annurev.earth.24.1.385

Silver, P. G., \& Holt, W. E. (2002). The mantle flow field beneath Western North America. Science, 295, 1054-1057. https://doi.org/10.1126/ science. 1066878

Silver, P. G., \& Long, M. D. (2011). The non-commutivity of shear wave splitting operators at low frequencies and implications for anisotropy tomography. Geophysical Journal International, 184, 1415-1427. https://doi.org/10.1111/j.1365-246x.2010.04927.x

Silver, P. G., \& Savage, M. K. (1994a). The interpretation of shear wave splitting parameters in the presence of two anisotropic layers. Geophysical Journal International, 119, 949-963. https://doi.org/10.1111/j.1365-246x.1994.tb04027.x

Silver, P. G., \& Savage, M. K. (1994b). The interpretation of shear-wave splitting parameters in the presence of two anisotropic layers. Geophysical Journal International, 119, 949-963. https://doi.org/10.1111/j.1365-246X.1994.tb04027.x

Skemer, P., \& Hansen, L. N. (2016). Inferring upper-mantle flow from seismic anisotropy: An experimental perspective. Tectonophysics, 668, 1-14. https://doi.org/10.1016/j.tecto.2015.12.003

Smith, D., Connelly, J. N., Manser, K., Moser, D. E., Housh, T. B., McDowell, F. W., \& Mack, L. E. (2004). Evolution of Navajo eclogites and hydration of the mantle wedge below the Colorado Plateau, southwestern United States. Geochemistry, Geophysics, Geosystems, 5(4), Q04005. https://doi.org/10.1029/2003gc000675

Smith, G. P., \& Ekström, G. (1999). A global study of $P_{n}$ anisotropy beneath continents. Journal of Geophysical Research, 104, 963-980. https://doi.org/10.1029/1998jb900021

Steinberger, B. (2000). Slabs in the lower mantle - Results of dynamic modelling compared with tomographic images and the geoid. Physics of the Earth and Planetary Interiors, 118, 241-257. https://doi.org/10.1016/s0031-9201(99)00172-7

Todd, V. R., Erskine, B. G., \& Morton, D. M. (1988). Metamorphic and tectonic evolution of the northern Peninsular Ranges batholith, southern California. In W. G. Ernst (Ed.), Metamorphic and crustal evolution of the northern Peninsular Ranges batholith, southern California, Rubey volume no. VIII. Prentice-Hall.

Townend, J., \& Zoback, M. D. (2004). Regional tectonic stress near the San Andreas fault in central and southern California. Geophysical Research Letters, 31, L15S11. https://doi.org/10.1029/2003GL018918

Usui, T., Nakamura, E., Kobayashi, K., Maruyama, S., \& Helmstaedt, H. (2003). Fate of the subducted Farallon plate inferred from eclogite xenoliths in the Colorado Plateau. Geology, 31(7), 589-592. https://doi.org/10.1130/0091-7613(2003)031<0589:fotsfp >2.0.co;2

Wang, K., Jiang, C., Yang, Y., Schulte-Pelkum, V., \& Liu, Q. (2020). Crustal deformation in southern California constrained by radial anisotropy from ambient noise adjoint tomography. Geophysical Research Letters, 47(12), e2020GL088580. https://doi.org/10.1029/2020GL088580

Wang, K., Sun, T., Brown, L., Hino, R., Tomita, F., Kido, M., et al. (2018). Learning from crustal deformation associated with the M9 2011 Tohoku-oki earthquake. Geosphere, 14, 552-571. https://doi.org/10.1130/ges01531.1

Wang, W., \& Becker, T. W. (2019). Upper mantle seismic anisotropy as a constraint for mantle flow and continental dynamics of the North American Plate. Earth and Planetary Science Letters, 514, 143-155. https://doi.org/10.1016/j.epsl.2019.03.019

Wei, M., Sandwell, D. T., \& Smith-Konter, B. (2010). Optimal combination of InSAR and GPS for measuring interseismic crustal deformation. Advances in Space Research, 46, 236-249. https://doi.org/10.1016/j.asr.2010.03.013

Xie, J., Ritzwoller, M. H., Brownlee, S. J., \& Hacker, B. R. (2015). Inferring the oriented elastic tensor from surface wave observations: Preliminary application across the western United States. Geophysical Journal International, 201(2), 996-1021. https://doi.org/10.1093/ gji/ggv054

Xie, J., Ritzwoller, M. H., Shen, W., \& Wang, W. (2017). Crustal anisotropy across eastern Tibet and surroundings modeled as a depth-dependent tilted hexagonally symmetric medium. Geophysical Journal International, 209(1), 466-491. https://doi.org/10.1093/gji/ggx004

Yan, Z., \& Clayton, R. W. (2007). Regional mapping of the crustal structure in southern California from receiver functions. Journal of Geophysical Research, 112(B5), B05311. https://doi.org/10.1029/2006JB004622 
Yang, W., \& Hauksson, E. (2013). The tectonic crustal stress field and style of faulting along the Pacific North America Plate boundary in Southern California. Geophysical Journal International, 194, 100-117. https://doi.org/10.1093/gji/ggt113

Yang, W., Hauksson, E., \& Shearer, P. (2012). Computing a large refined catalog of focal mechanisms for southern California (1981 2010): Temporal stability of the style of faulting. Bulletin of the Seismological Society of America, 102, 1179-1194. https://doi. org/10.1785/0120110311

Yu, Y., \& Zhao, D. (2018). Lithospheric deformation and asthenospheric flow associated with the Isabella anomaly in southern California. Journal of Geophysical Research: Solid Earth, 123, 8842-8857. https://doi.org/10.1029/2018JB015873

Yule, D., \& Sieh, K. (2003). Complexities of the San Andreas fault near San Gorgonio Pass: Implications for large earthquakes. Journal of Geophysical Research, 108(B11), 2548. https://doi.org/10.1029/2001jb000451

Zeng, X., \& Thurber, C. (2019). Three-dimensional shear wave velocity structure revealed with ambient noise tomography in the Parkfield, California region. Physics of the Earth and Planetary Interiors, 292, 67-75. https://doi.org/10.1016/j.pepi.2019.05.007

Zeng, Y., \& Shen, Z.-K. (2016). A fault-based model for crustal deformation, fault slip rates, and off-fault strain rate in California. Bulletin of the Seismological Society of America, 106, 766-784. https://doi.org/10.1785/0120140250

Zeng, Y., \& Shen, Z.-K. (2017). A fault-based model for crustal deformation in the western United States based on a combined inversion of GPS and geologic inputs. Bulletin of the Seismological Society of America, 107, 2597-2612. https://doi.org/10.1785/0120150362

Zhou, Q., Hu, J. S., Liu, L. J., Chaparro, T., Stegman, D., \& Faccenda, M. (2018). Western US seismic anisotropy revealing complex mantle dynamics. Earth and Planetary Science Letters, 500, 156-167. https://doi.org/10.1016/j.epsl.2018.08.015

Zhu, L., \& Kanamori, H. (2000). Moho depth variation in southern California from teleseismic receiver functions. Journal of Geophysical Research, 105(B2), 2969-2980. https://doi.org/10.1029/1999JB900322 